\title{
Reliability and Precision of Hip Proprioception Methods in Healthy Individuals
}

\author{
by
}

Anne Benjaminse, PT

BS, University of Groningen, the Netherlands, 2004

\author{
Submitted to the Graduate Faculty of \\ School of Health and Rehabilitation Sciences in partial fulfillment \\ of the requirements for the degree of \\ Master in Science
}

University of Pittsburgh 


\section{UNIVERSITY OF PITTSBURGH \\ SCHOOL OF HEALTH AND REHABILITATION SCIENCES}

This thesis was presented

by

Anne Benjaminse

It was defended on

April $14^{\text {th }}, 2008$

and approved by

Timothy C. Sell, PhD, PT, Assistant Professor

Scott M. Lephart, PhD, ATC, Associate Professor

John P. Abt, PhD, ATC, Assistant Professor

Anthony J. House, MS, ATC, CSCS, Doctoral Student

Thesis Director: Timothy C. Sell, PhD, PT, Assistant Professor 
Copyright $(\mathrm{C}$ by Anne Benjaminse 2008 


\title{
Reliability and Precision of Hip Proprioception Methods in Healthy Individuals
}

\author{
Anne Benjaminse, PT \\ University of Pittsburgh, 2008
}

The underlying risk factors for female anterior cruciate ligament (ACL) injuries are likely multifactorial. Poor neuromuscular and biomechanical control of the lower limb appears to be a primary contributor to the female ACL injury mechanism. Neuromuscular and biomechanical characteristics of the hip may significantly contribute to lower extremity function, since hip position and motion has been found to influence knee position and loads. Afferent proprioceptive signals from mechanoreceptors in the ACL play a vital role in dynamic joint stability of the knee. The same principle is valid for maintaining dynamic stability of the hip, however there has been limited research examining proprioception of the hip. Prior to investigating the contribution of hip proprioception to knee injuries, the reliability and precision of the desired hip proprioception methods must be established. The goal of this study was to establish the intersession and intrasession reliability and precision of threshold to detect passive motion, force sense and active joint position sense tests of the hip in healthy individuals. The results of this study indicate that a reliable and precise method of measuring hip threshold to detect passive motion (TTDPM) has been established. Further investigation is warranted to develop reliable and precise measurement methods for force sense (FS) and active joint position sense (JPS) measurements of the hip. 
TABLE OF CONTENTS

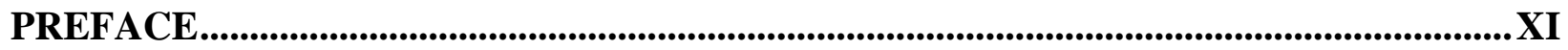

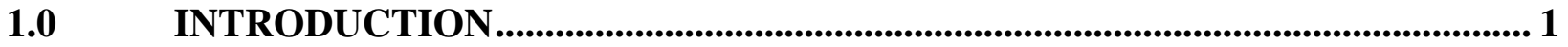

1.1 PROPRIOCEPTION AND NEUROMUSCULAR CONTROL ..................... 1

1.2 FUNCTIONAL STABILITY AND HIP PROPRIOCEPTION ....................... 2

1.2.1 Relationship of hip and lower extremity injuries............................................ 2

1.2.2 Relationship of hip and noncontact ACL injuries ......................................... 4

1.2.3 Importance of proprioception on functional stability ................................. 5

1.2.4 Functional stability and proprioception of the hip ....................................... 6

1.3 DEFINITION OF THE PROBLEM ....................................................................... 7

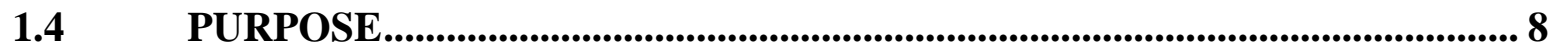

1.5 OBJECTIVES AND SPECIFIC AIMS .............................................................. 8

2.0 REVIEW OF LITERATURE ................................................................................... 10

2.1 PROPRIOCEPTION AND NEUROMUSCULAR CONTROL .................... 10

2.1.1 The sensorimotor system .................................................................................... 10

2.1.2 Classification and function of mechanoreceptors ........................................ 12

2.1.3 Measurement of proprioception ....................................................................... 16

$2.2 \quad$ HIP PROPRIOCEPTION................................................................................... 18

2.3 RELATIONSHIP OF HIP AND LOWER EXTREMITY INJURIES......... 21 
2.3.1 Muscular function...................................................................................... 21

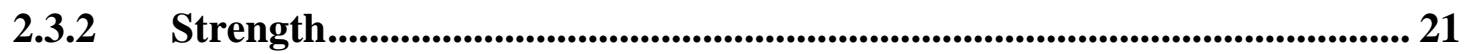

2.3.3 Proprioception.................................................................................................. 22

$2.4 \quad$ RELATIONSHIP OF HIP AND NONCONTACT ACL INJURIES ............ 23

$2.5 \quad$ METHODOLOGICAL CONSIDERATIONS.............................................. 25

2.5.1 Assessment of proprioception ...................................................................... 26

2.5.1.1 Justification of measured directions .................................................... 26

2.5.2 Joint position sense ............................................................................................ 28

2.5.3 Threshold to detect passive motion ................................................................. 28

2.5.4 Force sense ......................................................................................................... 29

3.0 MATERIALS AND METHODS ............................................................................. 31

EXPERIMENTAL DESIGN .............................................................................. 31

$3.2 \quad$ SUBJECT RECRUITMENT ............................................................................. 32

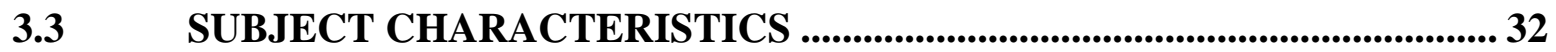

3.3.1 Inclusion Criteria ........................................................................................ 32

3.3.2 Exclusion Criteria ............................................................................................ 33

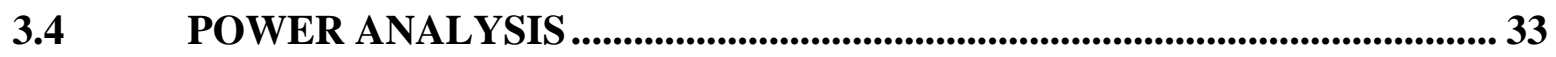

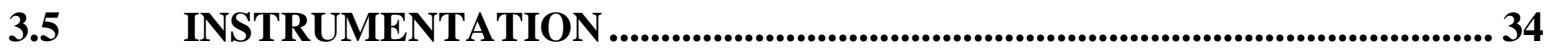

3.5.1 Biodex System 3 Multi-Joint Testing and Rehabilitation System ........... 34

3.5.2 PresSsino gradient sequential compression unit.......................................... 35

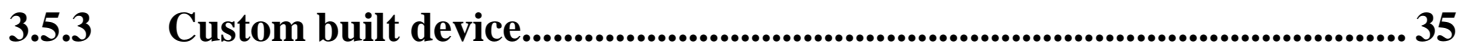

3.5.4 3D Vicon Motion Analysis System..................................................................... 36

TESTING PROCEDURES .................................................................................. 36 
3.6.1 Consent and demographic forms................................................................. 36

3.6.2 Proprioception testing ........................................................................... 40

3.6.2.1 Joint position sense in transverse plane (active) ................................... 41

3.6.2.2 Joint position sense in sagittal plane (active) ........................................ 43

3.6.2.3 Joint position sense in frontal plane (active) ......................................... 44

3.6.2.4 Threshold to detect passive motion in sagittal plane ........................... 46

3.6.2.5 Threshold to detect passive motion in frontal plane............................ 47

3.6.2.6 Force sense in sagittal plane....................................................................... 48

3.6.2.7 Force sense in frontal plane ..................................................................... 49

D.7 DATA REDUCTION AND ANALYSIS........................................................... 50

4.0 RESULTS …............................................................................................................... 52

4.1.1 Joint position sense ............................................................................................ 52

4.1.2 Threshold to detect passive motion .................................................................. 53

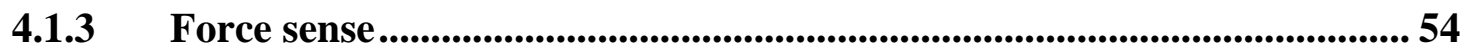

4.1.4 Hip ROM and generalized laxity.................................................................... 55

D.0 DISCUSSION ................................................................................................................... 57

5.1 RELIABILITY OF HIP PROPRIOCEPTION MEASURES ......................... 57

5.1.1 Joint position sense ............................................................................................. 57

5.1.2 Threshold to detect passive motion .................................................................. 59

5.1.3 Force sense ........................................................................................................ 60

5.1.4 Hip ROM and generalized laxity ..................................................................... 61

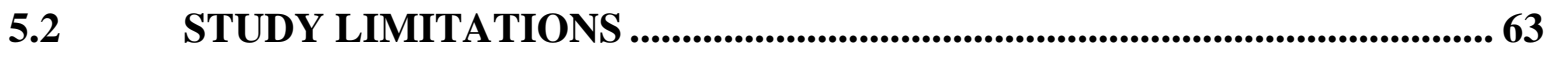

5.2.1 Instrumentation........................................................................................... 63 
5.2.2 Variability in performance.......................................................................... 64

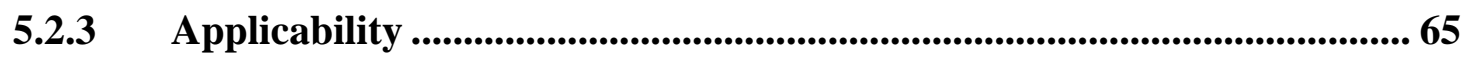

$5.3 \quad$ FUTURE RESEARCH......................................................................................66

C.4 CONCLUSIONS .................................................................................................... 67

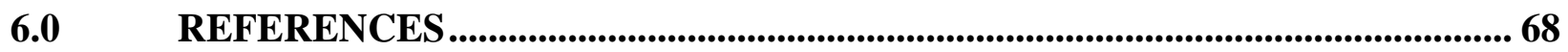

APPENDIX A : FLYER ................................................................................................................. 76

APPENDIX B : PARTICIPANT SCREENING LOG ................................................................ 77

APPENDIX C : INCLUSION EXCLUSION CRITERIA CHECKLIST .............................. 78

APPENDIX D : PROCEDURE CHECKLIST ................................................................... 79

APPENDIX E : NARRATIVE NOTE ......................................................................................... 81

APPENDIX F : DEMOGRAPIC INFORMATION ................................................................... 82

APPENDIX G : PHYSICAL EXAMINATION .............................................................................. 83

APPENDIX H : CORRELATION ANALYSIS .......................................................................... 84

APPENDIX I : BETWEEN DAY RELIABILITY OF HIP ROM MEASUREMENTS...... 85 


\section{LIST OF TABLES}

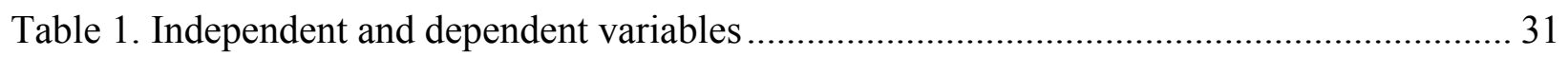

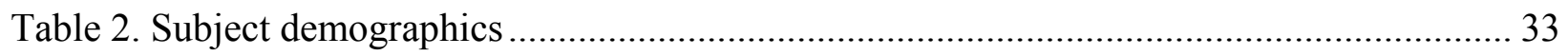

Table 3. Nine-point Beighton hypermobility score. ........................................................... 39

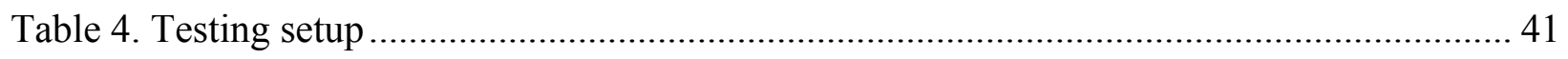

Table 5. Means and standard deviations (SD) of absolute errors for joint position sense........... 52

Table 6. Reliability and precision for joint position sense................................................ 53

Table 7. Means and standard deviations (SD) of absolute errors for threshold to detect passive

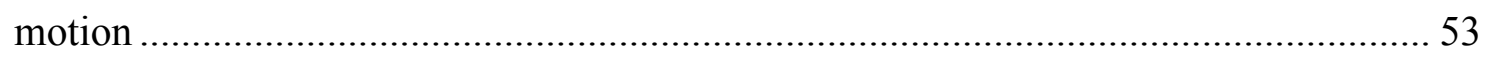

Table 8. Reliability and precision for threshold to detect passive motion................................ 54

Table 9. Means and standard deviations (SD) of absolute errors for force sense....................... 54

Table 10. Reliability and precision for force sense ...................................................... 55

Table 11. Hip range of motion dominant leg (average of day 1) …...................................... 55

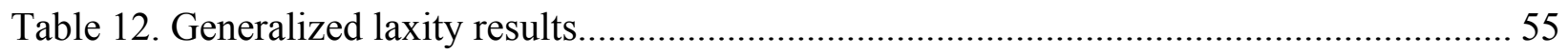




\section{LIST OF FIGURES}

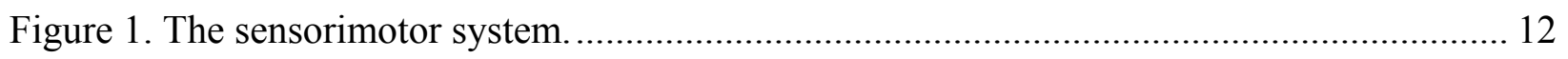

Figure 2. Custom built device for internal and external rotation....................................... 35

Figure 3. Testing set up for external rotation active JPS ............................................... 42

Figure 4. Testing set up for internal rotation active JPS .................................................. 42

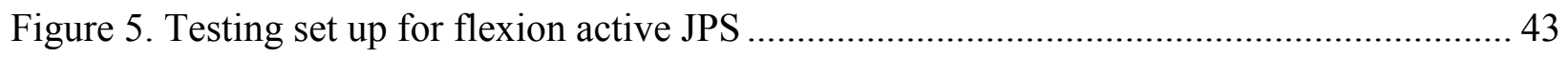

Figure 6. Testing set up for abduction active JPS ........................................................ 45

Figure 7. Testing set up for adduction active JPS .......................................................... 45

Figure 8. Testing set up for flexion / extension TTDPM................................................ 46

Figure 9. Testing set up for abduction / adduction TTDPM ............................................ 47

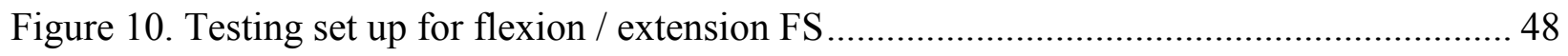

Figure 11. Testing set up for abduction / adduction FS ................................................. 49 


\section{PREFACE}

I would like to thank my research committee, Dr. Timothy C. Sell, Dr. Scott M. Lephart, Dr. John P. Abt and Anthony J. House for their considerable support and guidance throughout the entire process. Many thanks go out to my dissertation committee chair, Dr. Timothy C. Sell, whose efforts and guidance were exemplary and during all phases of my master's education.

I would also like to thank and recognize my colleagues Gordon Huang, Tony House and Yungchien $\mathrm{Chu}$ at the Neuromuscular Research Laboratory for their support and assistance. Working together with them was indispensable and I was fortunate to have a talented team around me. Having friends and colleagues assist by giving feedback over every aspect of the project as well as willingness to help during data collection will always be remembered and appreciated. Thanks for being there and providing some great memories.

I want to thank Dr. Freddie H. Fu for The Freddie H. Fu Graduate Research Award and the School of Health and Rehabilitation Sciences for the grant provided through the School of Health and Rehabilitation Sciences Research Development Fund, which provided funding for the completion of this project.

Finally, I would like to recognize my family and friends who provided encouragement and understanding throughout my education. 


\subsection{INTRODUCTION}

\subsection{PROPRIOCEPTION AND NEUROMUSCULAR CONTROL}

Proprioception is defined as the awareness of body position, orientation, movement and sensation of force. ${ }^{123}$ It is the afferent input arising from internal peripheral areas of the body to the central nervous system for processing that contribute to postural control, joint stability and several other conscious sensations. ${ }^{113}$ Proprioception is necessary to establish an accurate, efficient and coordinated response of the efferent system to the demands of the environment. ${ }^{31}$

The sensorimotor system is a subcomponent of the motor control system, which describes the sensory, motor and central integration and processing components involved in maintaining joint homeostasis during movements. ${ }^{73}$ The sensorimotor system incorporates all the afferent, efferent, and central integration and processing components involved in maintaining functional joint stability. The purpose of the sensorimotor system is to allow the body to integrate information to adjust posture and to refine neuromuscular responses to the environment for safe, balanced and appropriate movement during function. Proper integration of neural input is necessary for coordination of movement and position.

Neuromuscular control is the unconscious activation of dynamic restraints occurring in preparation for and in response to joint motion and loading. This is for the purpose of maintaining and restoring functional joint stability. ${ }^{114}$ Since proprioception and accompanying 
neuromuscular control mechanisms provide an important component for the establishment and maintenance of functional joint stability, ${ }^{76}$ one can assume that 'poor' hip proprioception in healthy subjects is related to decreased control of hip joint stability.

\subsection{FUNCTIONAL STABILITY AND HIP PROPRIOCEPTION}

\subsubsection{Relationship of hip and lower extremity injuries}

Hip musculature has many important functions during landing. Immediately following ground contact, the hip flexors act concentrically and bring the trunk's center of mass down and forward. This action decreases the lever arm between the trunk's center of mass and the knee joint center, decreasing the load on the knee extensors. ${ }^{18}$ Immediately following the concentric hip flexor activity, the hip extensors, including the hamstrings, create an eccentric hip extensor moment that first reduces the forward momentum of the trunk and then makes a second contribution to reduce the downward velocity of the body. ${ }^{18}$ From these two functions, a large hip extensor moment is generated that transfers tension through the biarticular hamstring muscles and dynamically stabilizes the knee. ${ }^{18}$ Also, the gluteus medius and maximus assist the quadriceps and hamstrings to adjust load upon the lower extremity during vertical jumping. ${ }^{10,33,}$ 130

Division I collegiate female athletes utilized less gluteus maximus and greater rectus femoris muscle activity compared to the male athletes during drop landings. ${ }^{137}$ Considering the functional anatomy, the gluteus maximus may play a role in directly controlling hip internal rotation, as well as indirectly controlling hip adduction. ${ }^{137}$ Also, an increased amount of hip 
adduction for females when performing a single-legged squat compared to male athletes has been found. ${ }^{138}$ This could indicate that females may have difficulty controlling the hip musculature, during a dynamic movement and that females rely more on the quadriceps muscles for control of the knee. When an athlete has poor hip control, especially in the gluteus medius muscle, the hip will tend to move into adduction when loaded. Once the hip moves into adduction, the femur internally rotates and the knee is placed into a valgus position. ${ }^{72,85,133}$ In addition to muscular control issues, females may have difficulty aligning the hip and femur properly due to anatomical differences. Females have been found to have larger Q-angles compared to males ${ }^{17,37,49,50,93,131}$ making the knee more vulnerable to a valgus position. Due to the greater pelvis width, more adduction is needed during single-legged landings to get the base of support under the center of mass. Research showed that the Q-angle correctly predicted lower extremity injury in $91 \%$ of the tested basketball players. ${ }^{120}$ Due to anatomical differences like Qangle and pelvis width, females are in all likelihood more vulnerable to hip adduction and hip internal rotation if neuromuscular control has failed to regulate this position.

Side-to-side maximum hip extension strength differences in female athletes who reported lower extremity injury have been found ${ }^{96}$ A specific description of the lower extremity injuries was not given in this study. Others prospectively found that athletes who did not sustain an injury (back/hip/thigh, knee or ankle/foot) were significantly stronger in hip abduction and external rotation strength. ${ }^{70}$ Ferris et al. did find that high school female basketball players had less hip external rotation strength than high school male basketball players. ${ }^{23}$ Hip external rotation strength therefore seems to be an important factor in maintaining functional joint stability of the lower extremity. 


\subsubsection{Relationship of hip and noncontact ACL injuries}

The underlying risk factors for female ACL injuries are likely multifactorial. Possible extrinsic factors include physical and visual perturbations, bracing and shoe-surface interaction. ${ }^{44}$ Possible intrinsic factors include anatomical, hormonal, neuromuscular and biomechanical characteristics. $^{44}$

Poor neuromuscular and biomechanical control of the lower limb appears to be a primary contributor to the female ACL injury mechanism. ${ }^{45}$ The differences between neuromuscular and biomechanical characteristics of the knee in male and female athletes have been explored extensively. ${ }^{26,43,82,86,94,110,124}$ However, similar variables have not been thoroughly explored at the hip. It is important to note that neuromuscular and biomechanical characteristics of the hip may also significantly contribute to lower extremity function, since hip position and motion has been found to influence knee position and loads. ${ }^{33,108,130}$

The hip plays an important role in the kinetic chain of the lower extremity. ${ }^{70,96,97,128,134,}$ 137, 138 Neuromuscular control of the hip joint in relation to ACL injury has received greater attention. $^{42,85,86,104,134,138}$ It has been suggested that hip control in the sagittal, frontal and transverse plane could be involved in the ACL injury mechanism. ${ }^{42}$ Different researchers have assessed kinematic variables of the hip as well as muscle recruitment related to the position of the whole lower extremity. ${ }^{23,43,72,86,104,137,138}$ these findings may indicate that females have difficulty controlling the hip during dynamic movement. As a result, females may be more vulnerable to large external forces on the lower extremity and a lack of control at the hip might place the ACL at an increased risk of injury. Considering the coupling between segments of the lower extremity, ${ }^{10,80,108}$ lesser activation of the proximal hip-stabilizing muscles may contribute to excessive valgus motion (derived from femoral internal rotation and adduction) observed in 
female athletes during landing in previous studies and frequently associated with noncontact ACL injuries. ${ }^{26,72,82}$ More specifically, hip abductor weakness could result in increased hip adduction or relatively decreased hip abduction during a dynamic lower extremity task. Especially in combination with increased hip internal rotation, this could lead to increased knee valgus. $^{72,85,133}$ This greater valgus may consequently result in higher ACL injury risk. ${ }^{45,} 47$ Others found a significant relationship demonstrating that pelvis and hip neuromechanical characteristics influence knee angles and moments during a vertical stop-jump task. ${ }^{23}$

\subsubsection{Importance of proprioception on functional stability}

Motor control is a plastic process that undergoes constant review and modification (ie. feedforward and feedback) based upon the integration and analysis of sensory input, efferent motor commands, and resultant movements. ${ }^{71}$ Proprioceptive information from joint and muscle receptors play an integral role in this process of maintaining functional joint stability. Joint and ligamentous mechanoreceptors are important for supraspinal sensorimotor control over dynamic joint stability. ${ }^{114}$

Freeman and Wyke attributed increased muscle activity, in response to joint mechanoreceptor stimulation, to activation of $\gamma$ motoneurons. ${ }^{27}$ Increased $\gamma$ motoneuron activation, which may occur from input arising from cutaneous or muscle sources as well as descending supraspinal commands, serves to heighten muscle spindle sensitivity. This leads to an increase in the resistance of perturbation and it assists the $\alpha$ motor neuron activation in decreasing the change of an injury. This happens by decreasing the electromechanical delay due to the creation of a certain amount of muscle stiffness. Secondly, the activation of $\gamma$ motor 
neurons already happens at force levels below those associated with tissue damage and nociception. $57,91,112,126$

Specifically, increased muscle stiffness and, therefore, enhanced joint stiffness, appears to be a beneficial characteristic for augmented functional joint stability. First, stiffer muscles should potentially resist sudden joint displacements more effectively. ${ }^{35,55,81,89}$ Although not all destabilizing forces may be entirely countered, many could potentially be lessened in magnitude, thereby reducing the incidence of joint subluxation and injury. This may be essential in maintaining functional stability when mechanical stability is deficient. ${ }^{114}$ Second, intrinsically stiffer muscles enhance the potential capacities of the extrinsic component. Stiffer muscles as a result of increased activation are also believed to transmit loads to muscle spindles more readily, reducing some of the lag time associated with initiation of reflexive activity. ${ }^{22,111}$ Some of the physical events contributing to electromechanical delay, such as the time interval between muscle activation and onset of segmental acceleration, are reduced in muscles with higher activation levels. ${ }^{32}$ Thus, not only is the initial resistance to joint displacement superior through heightened intrinsic stiffness, but the ability to recruit an improved reflexive response is also enhanced.

\subsubsection{Functional stability and proprioception of the hip}

Dynamic control of the hip is related to the position of the knee. Factors other than hip strength, like proprioception and core hip stability might be important in controlling knee

movements. ${ }^{128}$ Core stability has been defined as the ability to control the position and motion of the trunk over the pelvis to allow optimum production, transfer and control of force and motion to the terminal segment in integrated athletic activities. ${ }^{62}$ So, proprioceptive deficits in the body's 
core (ie. including hip) may contribute to decreased active neuromuscular control of the lower extremity, which may lead to valgus angulation and increased strain on the ligaments of the knee. ${ }^{6,45,47,83,137}$ Zazulak et al. investigated the relationship between core proprioception on lower extremity injuries. ${ }^{135,136}$ Active proprioceptive repositioning predicted knee injury status with $90 \%$ sensitivity and $56 \%$ specificity in female athletes. ${ }^{136}$ They concluded that impaired core proprioception predicted knee injury risk in female, but not male, athletes. ${ }^{136}$ The recent focus on functional joint stability of the hip in relation to the knee leads to a relatively new research area. Further investigation of the contribution of hip proprioception to functional knee stability is warranted. The knowledge of reliability of hip proprioception measurements will provide potential opportunity to look for injury risk factors and recovery following surgery. And the acquired baseline data might be valuable for further investigations in lower extremity and female ACL research. However, before looking into these relationships, it is necessary to know the accuracy of the hip proprioception measurement techniques.

\subsection{DEFINITION OF THE PROBLEM}

The afferent proprioceptive signals from mechanoreceptors in the ACL have been suggested to play a vital role in dynamic joint stability of the knee. ${ }^{75,113,114}$ One could assume that the same principle is valid for maintaining dynamic stability of the hip, however there has been limited research examining proprioception of the hip, with a majority focusing on proprioception in the elderly after hip fracture ${ }^{52,90}$ or total hip replacement. ${ }^{100,}{ }^{101}$ In addition, none of these studies investigated the reliability of measuring hip proprioception. This, however, is necessary before the contribution of hip proprioception to knee injuries can be investigated. 


\subsection{PURPOSE}

The purpose of this study is to establish the intersession and intrasession reliability and precision of threshold to detect passive motion (TTDPM), force sense (FS) and active joint position sense (JPS) of the hip in healthy individuals with no previous hip injuries or surgeries.

This study is important because: (1) No literature on reliability and precision data regarding hip proprioception is available. (2) No literature on hip proprioception in young healthy adults is available. An adequate approach necessitates well controlled reevaluation procedures and full presentation of reliability estimates. ${ }^{127}$ This study will therefore provide intra- and intersession intraclass correlation coefficient (ICC) and standard error of measurement (SEM) data, which might be valuable for further investigations in female ACL research, as well as in further research of proprioception of the hip after hip injuries, hip fractures or total hip replacements.

\subsection{OBJECTIVES AND SPECIFIC AIMS}

The objectives of this study were to establish intrasession and intersession reliability and precision of TTDPM, FS and JPS tests of the hip in healthy individuals with no previous hip injuries or surgeries. 
Specific Aim 1: To establish the intra- and intersession reliability and precision of measuring TTDPM and FS of the hip using the Biodex System 3 Multi-Joint Testing and Rehabilitation System (Biodex Medical Inc, Shirley, NY)

Specific Aim 2: To establish the intra- and intersession reliability and precision of measuring active JPS of the hip using the Vicon Motion Analysis System (Vicon Motion Systems, Inc., Centennial, CO). 


\subsection{REVIEW OF LITERATURE}

\subsection{PROPRIOCEPTION AND NEUROMUSCULAR CONTROL}

\subsubsection{The sensorimotor system}

Proprioception is defined as the awareness of body position, orientation, movement and sensation of force. ${ }^{123}$ It is the afferent input arising from internal peripheral areas of the body to the central nervous system for processing that contribute to postural control, joint stability and several conscious sensations. ${ }^{113}$ Proprioception is necessary to establish an accurate, efficient and coordinated response of the efferent system to the demands of the environment. ${ }^{31}$ There is much variability as to what constitutes the extent of proprioception in the human body, but for the purpose of this study; proprioception will end with the afferent input being delivered to the CNS via the appropriate neural pathways. ${ }^{73,113}$

The sensorimotor system is a subcomponent of the motor control system, which describes the sensory, motor and central integration and processing components involved in maintaining joint homeostasis during movements (Figure 1). ${ }^{73}$ The sensorimotor system incorporates all the afferent, efferent, and central integration and processing components involved in maintaining functional joint stability. This unconscious afferent somatosensory, visual, and vestibular input must be integrated and interpreted at the level of the cerebral cortex, brain stem, basal ganglia, 
cerebellum and spinal cord levels. ${ }^{31}$ Each processing center receives proprioceptive information and processes the information in its own unique way. ${ }^{73}$ At the cortical level, proprioceptive information is used to establish conscious awareness of posture, body position, and movement sense. At the spinal cord level, proprioception is used to grade a reflexive response through mono- and polysynaptic pathways. These reflexes are subject to descending pathways of motor control. $^{31,73,113}$ Finally the complex efferent response must be made through the fusimotor system $^{73,113}$ (Figure 1). The purpose of the sensorimotor system is to allow the body to integrate information to adjust posture and to refine neuromuscular responses to the environment for safe, balanced and appropriate movement during function. Proper integration of neural input is necessary for coordination of movement and position. Without proprioception, appropriate dynamic stabilization would not be possible.

Neuromuscular control is the unconscious activation of dynamic restraints occurring in preparation for and in response to joint motion and loading for the purpose of maintaining and restoring functional joint stability. ${ }^{114}$ Joint stability is the state of a joint remaining or promptly returning to proper alignment through equalization of forces and moments. This is accomplished through a complementary relationship between the static and dynamic components. ${ }^{114}$ Joint stability relies on these static and dynamic components. The static components include: ligaments, joint capsule, cartilage, bony geometry and friction. ${ }^{55,79}$ Feedforward and feedback neuromotor control over the muscles crossing the joint belong to the dynamic components. ${ }^{113}$ The interaction of static and dynamic mechanisms is mediated by the sensorimotor system (Figure 1) ${ }^{73}$ 


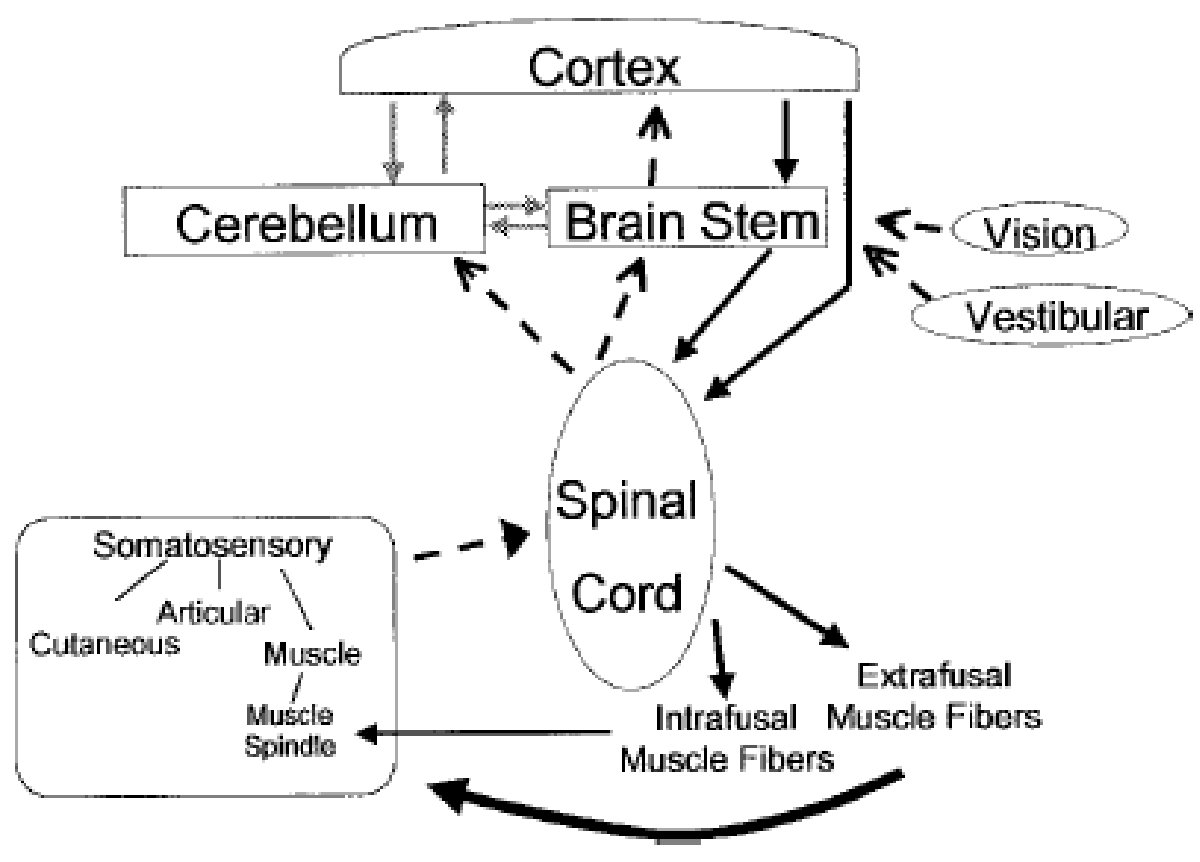

Figure 1. The sensorimotor system.

\subsubsection{Classification and function of mechanoreceptors}

The peripheral mechanoreceptors reside in the cutaneous, muscular, joint, and ligamentous tissues (Figure 1). ${ }^{73}$ Sensory systems code four aspects of a stimulus: ${ }^{48,54,56,57}$

1. Stimulus type (modality). All receptors of a single afferent neuron are sensitive to the same type of stimulus.

2. Stimulus intensity. An increased stimulus results in a larger receptor potential, leading to a higher frequency of action potential. Stronger stimuli also affect a larger area and recruit a larger number of receptors.

3. Stimulus location. Coded by site of the stimulated receptor. The precision of location, called acuity, is negatively correlated with the amount of convergence in ascending 
pathways, size of the receptive field and overlap with adjacent receptive fields. Response is highest at the center of receptive field since receptor density is the highest there. Using lateral inhibition, a process by which information from neurons at the edge of a stimulus is inhibited, acuity can be increased.

4. Stimulus duration. Rapid adapting receptors respond rapidly at the onset of stimulus but slow down or stop firing during the remainder of stimulus (they adapt quickly). They are important in signaling rapid change. Slow adapting receptors maintain their response at or near the initial level of firing through the duration of stimulus and are important in signaling slow changes.

The primary receptors (due to their encapsulated nature) were classified by Freeman and Wyke: Type 1: Ruffini corpuscles, Type 2: Pacini corpuscles and Type 3: Golgi organs. ${ }^{28}$ The free nerve endings were not described as one of the types of encapsulated nerve endings responsible for proprioception by Freeman and Wyke. ${ }^{28}$ The believe that free nerve endings (Type 4) are not only nociceptive receptors, but could also be mechanical in nature, playing a greater role in proprioception than previously believed, ${ }^{28}$ came later. ${ }^{34}$

Type 1 - Ruffini corpuscles

The Ruffini corpuscles are the most frequently described ${ }^{48}$ and are thought to detect joint limits. As a joint is moved into a limit of its movement, capsule stress increases, and Ruffini afferents are excited proportionally to the stress. They are arranged in clusters with a thickness of 5-8 $\mu \mathrm{m} .^{28,}{ }^{48}$ They are slow adapting receptors sensible for tension with a low stimulation 
threshold ${ }^{132}$ and are therefore considered to behave both as static and dynamic receptors. ${ }^{113}$ The axons are myelinated and have a conduction velocity of $10-20 \mathrm{~m} / \mathrm{s}$.

Type 2 - Pacini corpuscles

The afferent fibers of the Pacini receptors have a diameter of 8-12 $\mu \mathrm{m}$ and the myelinated axons of the receptors have a conduction rate of $25-50 \mathrm{~m} / \mathrm{s}$. Pacini receptors are inactive in immobilized joints and when the joint is moving with a constant velocity. They are sensitive though and become active in case of deceleration or acceleration of the joint. Their threshold is low and adaptation occurs rapidly. ${ }^{113}$

Type 3 - Golgi tendon organs

Golgi organs are spindle shaped and enveloped in a capsule of connective tissue, with a diameter of 13-17 $\mu \mathrm{m}$. Their myelinated fibers have a conduction rate of $75 \mathrm{~m} / \mathrm{s}$. Golgi organs are located near the myotendinous junction. They measure ligament and tendon tension and sense active tension within the myotendinous unit. This results in relaxation of the agonist muscle and contraction of the antagonist, hence, they can be considered as a tension control system. They also have a sense for joint position and movement. In extreme positions they fire through their Ib-afferents, thereby inhibiting the $\alpha$-motor neurons. Their adaptation occurs slowly. Their have a relatively high threshold to mechanical stress, but variable and depends on the cell milieu. ${ }^{28,48}$ 
Type 4 - Free nerve endings

These afferent sensory organs possess a large receptor field that may display significant deficits with damage to the free nerve endings. The unmyelinated axon has a diameter of about 0.5-5.0 $\mu \mathrm{m}$. They transmit mechanically- and/or chemically-triggered information about pain and inflammation. ${ }^{61}$ The free nerve endings are silent during normal, physiological conditions. Excessive mechanical force activates them. In addition, an inflammatory response induces biochemical changes, such as changes in histamine, prostaglandin, serotonin and bradykinin levels. These changes can activate the free nerve endings as they also have chemosensitive capacities. $^{28,48}$

Muscle spindles

Muscle spindles also need to be considered in proprioception during muscle length and tension changes. The muscle spindles act as a length control system. Activity of the mechanoreceptors stimulates $\gamma$ motor neurons, which then stimulate intrafusal muscle spindles. This tensions the central region containing the sensory receptor and the muscle spindle becomes more sensitive. The greater sensitivity of the spindle stimulates the contractile elements. The stimulation of the contractile elements results in greater muscle stiffness and therefore greater joint stiffness. ${ }^{55}$

Two classes of $\gamma$ motor neurons selectively control the sensitivity of the muscle spindles: 1) Controlling the dynamic sensitivity of the muscle spindles (dynamic $\gamma$ motor neurons) and 2) controlling the static sensitivity of the muscle spindles (static $\gamma$ motor neurons). ${ }^{54}$ The information from the muscle spindles is conveyed to the spinal cord (i.e., to reflex pathways, to motor neurons, and to ascending pathways) via two types of afferents; primary (spindle group la) 
and secondary (spindle group II) spindle afferents. Nuclear chain and nuclear bag fibers have been identified. The afferent nerve supply is made up by the primary annulospiral endings which are wrapped around the center of the intrafusal muscle fibers. The sensitivity of these intrafusal fibers is adjustable through the $\gamma$ motoneurons. ${ }^{55}$

Some of the metabolites produced by muscle contraction stimulate group III and IV muscle afferents. ${ }^{60,117,119}$ These afferents also have potent effect on both the dynamic and static $\gamma$ motoneurons. ${ }^{2,3}$ The $\gamma$ motor neurons regulate activity in the spindle afferents and particularly these primary muscle spindle afferents have been suggested to be of great importance in the regulation of muscle stiffness and proprioception. ${ }^{54}$

Controversy exist over the relative contribution to proprioception of muscle receptors versus joint receptors. ${ }^{57,} 59,66$ Both receptor types probably function as complementary components of the afferent system. It can also be noted that rotations into the limit of joint motion result in progressively smaller length changes in the muscles and in progressively larger tension in the joint capsule. In a sense, the capsule load sensors increase their response as the muscle sensors are losing their ability to detect angular displacement. ${ }^{34}$ Proprioception is an afferent component of the sensorimotor system which is essential for providing feedback in static and dynamic stabilization of each segment and the body's posture as a whole ${ }^{53}$ and therefore making it an appropriate avenue for clinical study.

\subsubsection{Measurement of proprioception}

Having defined terminology relevant to proprioception and sensorimotor control, it must be stated that direct measurement of proprioception is very difficult, if not impossible, to clinically perform since proprioception is exclusively an afferent phenomenon occurring both 
consciously and unconsciously within the body ${ }^{115}$ Proprioception, being a necessary component of the sensorimotor system, affords the researcher the opportunity to indirectly measure it through multiple sensorimotor pathways. The measurement of proprioception is divided into four modalities: 1) JPS - the ability to reproduce the same joint position, 2) kinesthesia measured by TTDPM - ability to detect the initiation of passive joint movement), 3) velocity sense (VS) ability to reproduce the same velocity and 4) FS - ability to reproduce the same force. This study focused on TTDPM, FS and active JPS, three frequently used modalities of measuring proprioception.

TTDPM was tested by slowly and passively moving the joint with the participant signaling when movement and direction is detected. When tested at slow angular velocity (0.5 $2.5^{\circ}$ /second), TTDPM is thought to selectively stimulate the Ruffini mechanoreceptors and joint receptors while minimally stimulating muscle receptors. In shutting down muscle activity, TTDPM is often chosen to assess afferent activity following ligament pathology. ${ }^{11,12,24,29,116} \mathrm{FS}$ was measured by assessing the ability to reproduce a reference torque. FS is thought to have two sources: the sense of tension generated by afferent feedback from the muscle, and the sense of effort generated centrally. ${ }^{107}$ Force sense reproduction should provide information regarding the integrity of muscle spindles and Golgi tendon organs per given effort. JPS was assessed by measuring the ability of the participant to actively reproduce a joint position. Active JPS is mostly influenced by muscle spindles and cutaneous information.

Mechanoreceptors are sensitive to the position a joint is in. For example, the Ruffini corpuscles are thought to detect joint limits. As a joint is moved into a limit of its movement, capsule stress increases, and Ruffini afferents are excited proportionally to the stress. ${ }^{48}$ Also, the Golgi tendon organs are sensitive to joint position and tension. They measure ligament and 
tendon tension and sense active tension within the myotendinous unit. ${ }^{48}$ They also have a sense for joint position and movement. In extreme positions they fire through their Ib-afferents, thereby inhibiting the $\alpha$-motor neurons. Considering this, the position of testing and the amount of range of motion (ROM) and the degree of generalized laxity available in a person will affect the sensitivity of the mechanoreceptors.

\subsection{HIP PROPRIOCEPTION}

The acetabular labrum of the hip has been shown to contain mechanoreceptors such as Ruffini endings, Pacinian corpuscles and free nerve endings ${ }^{64,109}$ Free nerve ending also have been found in the ligamentum capitis femoris. ${ }^{78}$ This is suggesting that the labrum and ligamentum capitis femoris may be involved in nociceptive and proprioceptive mechanisms. The mechanoreceptors are considered to register deep sensation of the joint and they accompany the other receptors located in the capsule of the hip joint. ${ }^{109}$ There are more precise results regarding the distribution and amount of these kind of receptors on animals. ${ }^{39}$ So far, detailed descriptions on the distribution of mechanoreceptors in the capsule and ligaments (eg. iliofemoral ligament) of the hip in human could not be found. This is however of importance as, despite of the above reported findings, it is still no complete agreement on the presence of mechanoreceptors in the labrum. And one could question how they are distributed and what their functional role is considering the high density of collagen bundles. For the knee, it has been suggested that mechanoreceptors are exclusively present in the loose tissue between the mechanical relevant

collagen bundles ${ }^{38}$ However, in the area of the labrum, there is hardly any loose tissue. This eliminates the possibility of the presence of such structures. In addition, the question arises if one 
should look for mechanoreceptors in heavy loaded structures anyways. The attachment of the labrum to the acetabulum will result in hardly any movement during normal physiological function. Still, a local compression caused by the periarticular musculoskeletal system will in all likelihood be registered by the above mentioned mechanoreceptors. ${ }^{109}$

The afferent proprioceptive signals from mechanoreceptors in the ACL have been suggested to play a vital role in dynamic joint stability of the knee. ${ }^{75,113,114}$ One could assume that the same principle is valid for maintaining dynamic stability of the hip. Since the adult hip resembles a well-constrained socket joint, the ligamentum capitis femoris may be part of an integral reflex system involved in joint protection, acting as a rein avoiding excessive motion potentially harmful to the joint. Excessive stress on the ligamentum capitis femoris may give afferent signals to inhibit further joint excursion by reactive muscular action. The presence of nerve endings in the acetabular labrum ${ }^{64}$ provides further evidence that intraarticular free nerve endings may help to prevent excessive joint motion causing damage to the acetabular rim and/or adjacent cartilage. According to this hypothesis, free nerve endings that are damaged by traumatic or degenerative lesions of the ligamentum capitis femoris lose their ability to transmit a mechanical stimulus as an efferent impulse. Due to loss of fine coordination, this absence of the muscular reflex might impair the protective function of the joint with ensuing micro- and macrotraumata.

To date, there has been limited research examining proprioception of the hip, with a majority focusing on proprioception in the elderly after hip fracture ${ }^{52,90}$ or total hip replacement. ${ }^{100,101}$ It has been shown that hip proprioception after hip fracture significantly improved following rehabilitation. ${ }^{90}$ Also, joint position sense of hip fracture patients was not found to be diminished compared with age-matched normal controls. ${ }^{52}$ Others showed that, 
compared with healthy age- and sex-matched controls, patients with total hip replacement did not have any proprioceptive deficit. ${ }^{100}$ Comparisons between ages did not reveal significant difference in hip JPS in the frontal plane between young and older subjects. ${ }^{102}$ In this study, accuracy was greater with smaller degrees of abduction. And active repositioning demonstrated higher precision compared to passive repositioning of the limb. ${ }^{102}$ The active contraction requires contribution of the muscle spindles in the hip abductors and may provide more afferent feedback regarding position than do the passive tasks..$^{30,34}$

Very little is known about the role of hip proprioception in healthy younger subjects. Since proprioception and accompanying neuromuscular control mechanisms provide an important component for the establishment and maintenance of functional joint stability, ${ }^{76}$ one can assume that 'poor' hip proprioception in healthy subjects is related to decreased control of hip joint stability. Considering the coupling of segments, ${ }^{10}, 80,108,130$ this decreased neuromuscular and biomechanical control of the hip could predispose to a knee valgus position ${ }^{72}$, 85,133 and therefore to ACL injury, ${ }^{45,47}$ especially due to hip adduction and hip internal rotation motions. However, this has not been studied yet. In order to gain more knowledge of the role of the hip related to lower extremity injuries and specifically the ACL injury mechanism examining proprioceptive characteristics of the hip is useful. 


\subsection{RELATIONSHIP OF HIP AND LOWER EXTREMITY INJURIES}

\subsubsection{Muscular function}

Hip musculature has many important functions during landing. Immediately following ground contact, the hip flexors act concentrically to bring the trunk's center of mass down and forward. This action decreases the lever arm between the trunk's center of mass and the knee joint center, decreasing the load on the knee extensors. Immediately following the concentric hip flexor activity, the hip extensors, including the hamstrings, create an eccentric hip extensor moment that first reduces the forward momentum of the trunk and then makes a second contribution to reduce the downward velocity of the body. From these two functions, a large hip extensor moment is generated that transfers tension through the biarticular hamstring muscles and dynamically stabilizes the knee. ${ }^{18}$ Also, the gluteus medius and maximus assist the

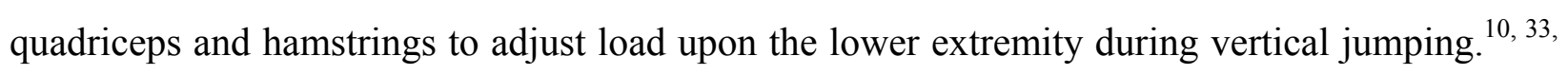
${ }^{130}$ Significant relationships demonstrating that pelvis and hip neuromechanical characteristics influence knee angles and moments during a vertical stop-jump task have been found. ${ }^{23}$

\subsubsection{Strength}

Nadler et al. found a significant difference in side-to-side symmetry of maximum hip extension strength in female subjects who reported lower extremity injury as compared to those who did not. ${ }^{96}$ Side-to-side difference in hip strength, however, did not differ between male athletes, regardless of reported lower extremity injury status. A specific description of the lower extremity injuries was not given. Leetun et al. prospectively compared core stability measures 
between genders and between athletes who reported an injury during their season versus those who did not. ${ }^{70}$ The injuries reported in this study are back/hip/thigh, knee and ankle/foot injuries. They examined hip abduction, hip external rotation, side bridge and back extension strength. They found that athletes who did not sustain an injury were significantly stronger in hip abduction $($ males $=31.6+/-7.1 \% \mathrm{BW}$, females $=28.6+/-5.5 \% \mathrm{BW})$ and external rotation $($ males $=20.6+/-4.2 \% \mathrm{BW}$, females $=17.9+/-4.4 \% \mathrm{BW})$ strength. Hip external rotation was the only predictor of injury status $(\mathrm{OR}=0.86,95 \% \mathrm{CI}=0.77,0.097)$ in this study. It is interesting to note that Ferris et al. did find that females had less hip external rotation strength than males. ${ }^{23}$ Hip external rotation strength therefore seems to be an important factor in maintaining functional joint stability of the lower extremity.

\subsubsection{Proprioception}

Dynamic stability of an athlete's knee depends on accurate sensory input and appropriate motor responses to meet the demands of rapid changes in trunk position during cutting, stopping, and landing movements. ${ }^{46,47}$ Dynamic stability may be operationally defined as the ability of the knee joint to maintain position (static stability) or intended trajectory (dynamic stability) after internal or external disturbance. ${ }^{135}$ Proprioceptive deficits in the body's core may contribute to decreased active neuromuscular control of the lower extremity, which may lead to valgus angulation and increased strain on the ligaments of the knee. ${ }^{6,45,47,83,137}$ Zazulak et al. investigated the relationship between core proprioception on lower extremity injuries. ${ }^{135,} 136$ Deficits in active JPS were observed in female athletes with knee injuries $\left(2.2^{\circ}\right)$ and ligament / meniscal injuries $\left(2.4^{\circ}\right)$ compared with uninjured female athletes $\left(1.5^{\circ}, P \leq .05\right) .{ }^{136}$ For each degree increase in average active proprioceptive repositioning error, a 2.9-fold increase in the 
odds ratio of knee injury was observed, and a 3.3-fold increase in odds ratio of ligament / meniscal injury was observed $(P \leq .01)$. Active proprioceptive repositioning predicted knee injury status with $90 \%$ sensitivity and $56 \%$ specificity in female athletes. ${ }^{136}$ They concluded that impaired core proprioception predicted knee injury risk in female, but not male, athletes. ${ }^{136}$ Core stability has been defined as the ability to control the position and motion of the trunk over the pelvis to allow optimum production, transfer and control of force and motion to the terminal segment in integrated athletic activities. ${ }^{62}$ So, even though Zazulak et al. did not include the pelvis in their research, their results point towards the importance of adequate control of the trunk ánd the pelvis in protecting the more distal joints of the lower extremity. Inadequate neuromuscular control of the body's core may lead to uncontrolled trunk displacement during athletic movement, which in turn may compromise dynamic stability of the lower extremity, increased abduction torque at the knee, and result in increase strain on the knee ligaments and lead to injury. $6,47,83,137$

\subsection{RELATIONSHIP OF HIP AND NONCONTACT ACL INJURIES}

Recent literature suggests that control of hip is important to noncontact ACL injuries. Zeller et al. found that females had significantly more hip adduction, flexion and external rotation than men during a single leg squat. ${ }^{138}$ These factors, together with more dorsiflexion and pronation of the ankle and less trunk lateral flexion, were associated with a decreased ability of the female to maintain a varus knee position during the squat as compared with the male.

Also, during the landing of a stop-jump task, hip joint motion at landing appears to be an important technical factor that affects ACL loading. ${ }^{134}$ For the planting leg during side-step 
cutting maneuvers, females have shown significantly larger knee valgus moments than males. ${ }^{85}$ In this study, a greater peak valgus moment was associated with larger initial hip flexion and internal rotation and with a larger knee valgus angle at initial contact. This peak valgus in females was significantly more sensitive to initial contact postures than in males, with small changes in these initial values resulting in relatively large changes in the valgus moment. Pollard et al. and McLean et al. conducted research on side-step cutting maneuvers also showing less hip abduction $^{86,104}$ and flexion ${ }^{86}$ in females compared to males. As explained previously, this could potentially lead to injurious position for the knee.

It has been proposed that weak hip musculature could result in increased hip adduction or relatively decreased hip abduction. ${ }^{85}$, 104 Hip abductor weakness could result in increased hip adduction or relatively decreased hip abduction during a dynamic lower extremity task in combination with increased knee valgus. This may consequently result in higher ACL injury risk. $^{45,47}$

In the study by Leetun et al. one female athlete experienced a season-ending injury to her ACL. It is interesting to note that this athlete demonstrated preseason deficiencies in each core stability test: hip abduction, hip external rotation, side bridge and back extension. This individual was unique in that she was well below the average performance of females who reported an injury as well as to those who did not. ${ }^{70}$

In the study by Zazulak et al. females utilized decreased gluteus maximus and increased rectus femoris muscle activity compared to males. ${ }^{137}$ The gluteus maximus may play a role in directly controlling hip internal rotation, as well as indirectly controlling hip adduction.

Rozzi et al. demonstrated that healthy female athletes recorded a significantly $(P=0.001)$ greater EMG area under the curve of the first contraction of the lateral hamstrings compared to healthy 
male athletes subsequent to the deceleration from a single leg drop landing. ${ }^{118}$ It has been suggested that this might result in a muscular disbalance in the frontal plane and could lead to excessive external rotation of the tibia, which both may place the knee in an ACL injury risk

position. ${ }^{63,83}$ However, according to Simonsen et al., since the hamstring muscles are shortening rapidly during the landing, even a maximal activation of the hamstrings would have a marginal effect due to the force-velocity relation. ${ }^{125}$

Zeller et al. found that uninjured female athletes had an increased amount of hip adduction when performing a single-legged squat compared to male athletes. ${ }^{138}$ This could indicate that women may have difficulty controlling the hip musculature, especially the gluteus medius muscle, during a dynamic movement, demonstrating females may rely more on the quadriceps muscles for control of the knee. When an athlete has poor hip control, especially in the gluteus medius muscle, the hip will tend to move into adduction when loaded. Once the hip moves into adduction, the femur internally rotates and the knee is placed into a valgus position. The combination of these events places the athlete into the "position of no return," as described by Ireland..$^{51}$

\subsection{METHODOLOGICAL CONSIDERATIONS}

Proprioception can be assessed in numerous ways. The three modalities used in this study are the modalities most used in clinical research. Most of it has been applied to the knee, ankle and shoulder joints. There are strengths and weaknesses associated with each of these methodologies. This section of the chapter will review what the literature reports on the 
difficulties associated with the methodology and will provide a theoretical basis for the reason of the chosen investigation techniques.

\subsubsection{Assessment of proprioception}

The Biodex Systems 3 (Biodex Inc., Shirley, New York) has been widely used for the measurement of strength and endurance for numerous joints. Reliability data are described per modality in paragraph 2.5.2, 2.5.3 and 2.5.4 and in the instrumentation section. It is important to note that in order to externally assess proprioception, conscious control must be examined. This is likely an incomplete picture since proprioception is used in an unconscious manner during function. As has been demonstrated previously, high correlations between submodalities of proprioception is lacking in the literature ${ }^{36}$ suggesting the difficulty that may be encountered by drawing strong conclusions from the data collected.

\subsubsection{Justification of measured directions}

Hip position does in all likelihood show an association with sustaining an ACL injury considering the coupled motions between different segments of the lower extremity. ${ }^{10,80,108,130} \mathrm{~A}$ greater external peak valgus moment is associated with larger hip flexion and hip internal rotation at initial contact and with larger knee valgus angle at initial contact. ${ }^{85}$ As such, hip joint

motion appears to be an important factor that affects the knee and ACL loading. ${ }^{134}$ Hip motion in the sagittal, frontal and transverse planes was investigated. 
Sagittal plane - Hip motion in the sagittal plane is of importance as the peak impact posterior ground reaction force (GRF) during the landing is significantly correlated with the hip flexion motion. ${ }^{133}$ Peak posterior GRF significantly affects the peak proximal tibia anterior shear force $^{134}$ and proximal anterior tibia shear force is considered the major ACL loading mechanism. ${ }^{83,121,122}$ Maximum ACL strain occurs at the peak GRF $^{16}$ and in smaller degrees of knee flexion. ${ }^{25,} 40$ These relationships suggest that hip and knee joint angles may affect the loading on specific joint structures and are also indicating that increasing knee flexion during landing is important for reducing the risk of sustaining non-contact ACL injuries. ${ }^{134}$

Frontal plane - A tendency toward hip adduction can contribute to a valgus position of the knee. A relative weakness of the hip abduction musculature could contribute to this.

Transverse plane - Considering the coupling segments of the lower extremity a combination of femoral internal rotation and adduction, which contribute to a valgus position is to be expected in the closed kinetic chain. ${ }^{72,137}$ The role of decreased hip internal rotation (or increased hip external rotation) in relation to the ACL injury risk is not well understood. ${ }^{86,138}$

As the different modalities (TTDPM, FS, active JPS) contain different, but overlapping, functions in proprioception and controlling the joint, all these three modalities were investigated. The positions investigated (see section 3.5) represent important angles in respect to knee injuries, as has been discussed before. Even though tested in a controlled manner, this gives us valuable information on how subjects are able to control the hip in these important positions.

The measurement of proprioception is divided into four modalities: 1) JPS - the ability to reproduce the same joint position, 2) kinesthesia measured by TTDPM - ability to detect the initiation of passive joint movement), 3) velocity sense (VS) - ability to reproduce the same 
velocity and 4) FS - ability to reproduce the same force. This study focused on TTDPM and FS and active JPS, three frequently used modalities of measuring proprioception.

\subsubsection{Joint position sense}

3D Motion analysis was used to measure active JPS. Motion analysis has been used in measuring proprioception, ${ }^{14,102}$ however all three directions of the hip JPS using motion analysis has not been conducted.

Joint position sense at the shoulder has been reported to have good intraclass correlation coefficients, ${ }^{20} .981$ with the joint in $90 \%$ of IR ROM and .984 with the joint at $90 \%$ of ER ROM. Our laboratory results have shown an intrasession ICC (SEM) of $0.71 \pm 0.27\left(1.45 \pm 0.63^{\circ}\right)$ and an intersession ICC (SEM) of $0.36 \pm 0.31\left(1.56 \pm 0.68^{\circ}\right)$ for flexion and extension for the knee. ${ }^{98}$ For knee rotation, the intrasession ICC (SEM) was $0.64 \pm 0.20\left(1.48 \pm 0.67^{\circ}\right)$ and the intersession ICC $(\mathrm{SEM})$ ranges were $0.49 \pm 0.19\left(0.95 \pm 0.28^{\circ}\right) .{ }^{99}$

\subsubsection{Threshold to detect passive motion}

The Biodex has also been used in numerous studies for sensorimotor assessment. Traditionally, speeds of ranging between $0.5-2.0^{\circ} / \mathrm{s}$ have been used to target slow adapting mechanoreceptors in TTDPM studies ${ }^{103}$ and the Biodex System 3 currently has been equipped with software allowing the passive mode of assessment to be slowed to $0.25^{\circ} / \mathrm{s}$ making it more appropriate for assessing TTDPM more precisely and accurately. A previous reliability study revealed that the ICC values of knee TTDPM was reported to be 0.92 while the precision was not reported in the study. ${ }^{74}$ More recently Ageberg et al. found that measuring TTDPM closer 
towards terminal knee extension is more reliable in healthy subjects than at other points in the ROM. ${ }^{1}$ For the knee, TTDPM has previously been shown to have good test-retest reliability for the flexion and extension directions ${ }^{74,98}$ and also for rotational directions. ${ }^{99}$ The intrasession ICC (SEM) for flexion and extension in one of those studies was $0.86 \pm 0.07\left(0.25 \pm 0.07^{\circ}\right)$ and the intersession ICC (SEM) was $0.80 \pm 0.11\left(0.26 \pm 0.09^{\circ}\right) .{ }^{98}$ The intrasession ICC (SEM) for knee internal and external rotation has been reported as $0.75 \pm 0.06\left(0.33 \pm 0.05^{\circ}\right)$ and the intersession ICC (SEM) was $0.84 \pm 0.09\left(0.23 \pm 0.09^{\circ}\right) .{ }^{99}$ Reliability data for the TTDPM for the hip are not yet available.

\subsubsection{Force sense}

The Biodex Systems 3 has the capacity to be used for force appreciation. While the software has not been specifically designed for this purpose, modifications of standard protocols allow researchers to perform multiple repetition trials. The accuracy of force replication can be assessed with alteration of visual cues (ie. withholding visual feedback during the force replication trial). This specific submodality of proprioception has not been as widely studied in the hip and knee literature; therefore, its response to injury and treatment has received less critical inquiry than JPS and kinesthesia. There are a few studies on FS reproduction; the reliability and precision of these tests in the hip joint are not yet available. Instead, one study evaluated the force sense and reliability and precision at the ankle joint, and reported to have ICC and SEM of 0.84-0.89 and 0.97-2.42, respectively. ${ }^{19}$ Also, force sense has been reported to have good intraclass correlation coefficients in the shoulder, .981 with the joint in $90 \%$ of IR ROM and .978 with the joint at $90 \%$ of ER ROM. ${ }^{20}$ Our laboratory force sense data on knee flexion and extension showed an intrasession and intersession ICC (SEM) of $0.82 \pm 0.10$ 
$(1.06 \pm 0.51 \mathrm{Nm})$ and $0.79 \pm 0.18(0.94 \pm 0.68 \mathrm{Nm})$ respectively. ${ }^{99}$ For knee rotation, the intrasession ICC (SEM) was $.80 \pm 0.08(0.36 \pm 0.10 \mathrm{Nm})$ and the intersession ICC (SEM) ranges were $0.49 \pm 0.19\left(0.95 \pm 0.28^{\circ}\right) .{ }^{99}$ 


\subsection{MATERIALS AND METHODS}

\subsection{EXPERIMENTAL DESIGN}

This study was a descriptive intrasession and intersession reliability and precision study and examined the intersession and intrasession reliability and precision of TTDPM, FS and active JPS. Reliability is defined as the degree of consistency with which an instrument or rater measures a variable. ${ }^{105}$ Precision is defined as a measure made so as to vary minimally from a set standard. ${ }^{92}$ The intersession reliability and precision (between days) in healthy individuals with no previous hip injury was assessed to set the normative values for all proprioception tests. Also, the intra-session reliability and precision was assessed by comparing trials within the same session (between trials). The intrasession reliability and precision was used to assess how much variability each individual has in all tests. Independent and dependent variables are listed in Table 1.

Table 1. Independent and dependent variables

\begin{tabular}{|l|l|l|}
\hline Type of test & Independent variables & Dependent variables \\
\hline JPS & $\begin{array}{l}\text { Trial and } \\
\text { inter- and intrasession }\end{array}$ & $\begin{array}{l}\text { Absolute error in } \\
\text { A } \text { between trials } \\
\text { Absolute error in }\end{array}{ }^{\circ}$ between sessions \\
\hline TTDPM & $\begin{array}{l}\text { Trial and } \\
\text { inter- and intrasession }\end{array}$ & $\begin{array}{l}\text { Absolute error in } \\
\text { Absolute error in }{ }^{\circ} \text { between trials }\end{array}$ \\
\hline FS & $\begin{array}{l}\text { Trial and } \\
\text { inter- and intrasessions }\end{array}$ & $\begin{array}{l}\text { Absolute error in Newton-meters between trials } \\
\text { Absolute error in Newton-meters between sessions }\end{array}$ \\
\hline
\end{tabular}




\subsection{SUBJECT RECRUITMENT}

Subjects were recruited for this study primarily by word of mouth. Potential subjects who presented to the lab received information about the study. If they indicated an interest and appeared to fit the basic eligibility, they were invited to a screening/ first study visit. Flyers (Appendix A) were created, however recruitment went well and there was no need to post the ad. No subject attrition occurred; therefore, all 20 subjects who started the testing procedures completed data collection. A participant screening log was used to keep track of each subject's visit dates (Appendix B).

\subsection{SUBJECT CHARACTERISTICS}

Data were collected on 20 subjects. Subject characteristics are presented in Table 2. Leg dominance was defined by the preferred jumping leg. Inclusion and exclusion criteria were checked prior to testing (Appendix C) and were as follows:

\subsubsection{Inclusion Criteria}

1) Subjects were between 18 and 40 years old

2) Subjects had no history of major lower extremity injury or surgery

3) Subjects had no history of hip injuries

4) Subjects were physically active (at least 20-30 min activity 3 times/wk) 


\subsubsection{Exclusion Criteria}

1) Subjects with insulin dependent diabetes mellitus, rheumatologic disorder, cerebral vascular disorder, or any other central or peripheral disease that might interfere with sensory input

2) Previous history of cardiovascular or pulmonary disease

3) Uncontrolled metabolic disorder

4) Subjects with previous compartment syndrome or any vascular conditions to their lower leg

5) Currently and knowingly pregnant females (any female subject who is unable to definitively state that she is not pregnant). And also females who have been pregnant within the past two years

6) Subjects with any pain with maximal muscle contractions

7) Subjects with any skin irritations or abrasion and/or any history of allergy to adhesive tape

Table 2. Subject demographics

\begin{tabular}{|l|c|}
\hline & Mean (SD) \\
\hline Age (years) & $23.70(3.05)$ \\
\hline Height $(\mathrm{cm})$ & $168.98(8.79)$ \\
\hline Mass $(\mathrm{kg})$ & $69.39(10.79)$ \\
\hline Tegner & $6.10(1.33)$ \\
\hline
\end{tabular}

\subsection{POWER ANALYSIS}

This is a reliability study and was designed to determine the intra- and intersession reliability and precision of hip proprioception testing. No study has established reliability and precision data before for the hip joint on the Biodex System 3 Multi-Joint Testing and 
Rehabilitation System (Biodex Medical Inc, Shirley, NY) and utilizing Vicon Motion Analysis System (Vicon Motion Systems, Inc., Centennial, CO). We could therefore not use previous data in order to determine our sample size. We decided to include 20 subjects, based on previous reliability data for the same proprioception modalities ${ }^{69,77,99}$ and on the same device. ${ }^{69,99}$

\subsection{INSTRUMENTATION}

\subsubsection{Biodex System 3 Multi-Joint Testing and Rehabilitation System}

The Biodex System 3 Multi-Joint Testing and Rehabilitation System (Biodex Medical Inc, Shirley, NY) was used to collect the TTDPM and FS data of the hip. This is an instrumented dynamometer that is able to assess applied torque in an isometric mode. Calibration of the Biodex dynamometer was performed according to the specifications outlined by the manufacturer's service manual. In this study the reliability of the equipment was tested utilizing a calibrated weight. Trial-to-trial and day-to-day reliability of position $\left(^{\circ}\right)$ of the criterion measure has been reported as being 0.99 (ICC) and 0.45 - 0.60 (SEM) and 0.99 (ICC) and 2.01 (SEM) respectively. ${ }^{21}$ Trial-to-trial reliability of torque $(\mathrm{Nm})$ of the criterion measure has been reported as being 1.00 (ICC) and $0.00(\mathrm{SEM}) .{ }^{21}$ Day-to-day reliability of torque (Nm) of the criterion measure was not reported in this study. 


\subsubsection{PresSsino gradient sequential compression unit}

A PresSsino gradient sequential compression unit and a compression sleeve (Chattanooga group, Hixson, TN) were used during the TTDPM test. The inflated pneumatic sleeve was placed around the entire leg to minimize any tactile feedback between the dynamometer and the limb during the threshold to detect motion measurements.

\subsubsection{Custom built device}

A custom built device was used for the active JPS testing (Figure 2). Subjects stood with one foot on a freely rotating turntable to be able to either internally or externally rotate the hip. The turntable had pre-set internal and external rotation range of motions. It included balance aids to comfort the subjects. The subjects were instructed to just slightly hold the aids and focus on full weight bearing on both legs.

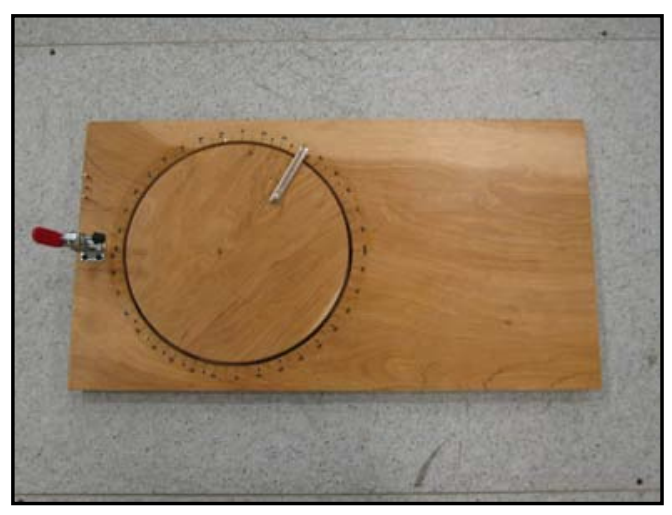

Figure 2. Custom built device for internal and external rotation. 


\subsubsection{D Vicon Motion Analysis System}

Hip joint angles during active JPS were determined and calculated utilizing the Vicon Motion Analysis System (Vicon Motion Systems, Inc., Centennial, CO). It is a 3D analysis system with eight high-speed $(200 \mathrm{~Hz})$ infrared cameras. The cameras utilize infrared lights and are only capable of collecting reflections from reflective materials. The system recreated 3D coordinate data from the eight individual cameras in order to quantify movement during the test. Anthropometric measurements, reflective markers and coordinate data collected from the camera recordings allowed for the calculation of the joint centers of rotation (ankle, knee, and hip).

\subsection{TESTING PROCEDURES}

\subsubsection{Consent and demographic forms}

Each subject signed an informed consent form approved by the University Institutional Review Board prior to the first testing session. A procedure checklist was kept up to date throughout the whole testing session (Appendix D). Each consent session did end with signing the narrative note form (Appendix E). All subjects attended two testing sessions, lasting approximately two hours each. In addition to standard demographic information, the subject's activity level was assessed with the Tegner activity level form (Appendix F), which is a general measure of activity level from level 0 (most sedentary) to level 10 (active in competitive sports with sudden stopping and twisting movements). 
Generalized laxity and hip range of motion testing was collected (Appendix G). Generalized laxity testing using the Beighton hypermobility score (Table 3) ${ }^{5,13}$ Fifth-finger extension was measured using a medium-sized, plastic, 8-in $(20.32-\mathrm{cm})$ goniometer with 1degree increments and knee and elbow extension using a large, plastic, 12-in (30.48-cm) goniometer with 1-degree increments. Trunk and hip flexion and thumb opposition was evaluated by the ability to complete a specific task (see below); therefore, no measurement device is needed for these tests. All measurements were performed bilaterally, except for trunk flexion.

Fifth Metacarphophalangeal Joint Extension

The fifth-finger extension test was demonstrated by the examiner, and then the fifth finger was passively extended by the subject. The distal portion of the fifth metacarpal was stabilized with the thumb of the opposite hand, while the tip of the fifth finger was extended by the subject using the index or middle finger as far as possible without pain. Goniometric measurements were taken with the fulcrum over the center of the metacarpophalangeal joint, the distal arm along the length of the finger, and the proximal arm along the fifth metacarpal. Fifthfinger hyperextension greater than $90^{\circ}$ resulted in a score of 1 . Hyperextension of $90^{\circ}$ or less results in a score of 0 .

\section{Wrist Flexion and Thumb Opposition}

The thumb-opposition test was demonstrated by the examiner and then done passively by the subject. The subject stabilized the distal portion of the forearm with the thumb of the opposite hand, and the thumb being tested was passively abducted by the fingers of the opposite 
hand toward the volar aspect of the forearm with the wrist in flexion. If the thumb could be abducted to touch the forearm, then the score was 1. Opposition less than this resulted in a score of 0 .

\section{Elbow Extension}

The elbow extension test was performed with the subject's shoulder abducted to approximately $80^{\circ}$ and the forearm supinated. The rater then stabilized the proximal elbow from the posterior side while applying a gentle force to the subject's palmar wrist to achieve passive end-range extension. The center of the fulcrum was placed over the lateral epicondyle of the humerus, and the distal arm of the goniometer was positioned along the lateral midline of the forearm and aligned with the radial styloid process. The proximal arm was positioned along the lateral midline of the subject's humerus. Hyperextension of the elbow greater than $10^{\circ}$ resulted in a score of 1 . Hyperextension of the elbow less than $10^{\circ}$ resulted in a score of 0 .

\section{Knee Extension}

The knee extension test was conducted in supine with 1 or 2 towel rolls placed under the ankle. The fulcrum of the goniometer was placed over the lateral epicondyle of the femur, and the proximal arm was aligned with the lateral midline of the femur, using the greater trochanter for reference. The distal arm was aligned with the lateral malleolus. Hyperextension of the knee greater than $10^{\circ}$ resulted in a score of 1 . Hyperextension of the knee less than $10^{\circ}$ resulted in a score of 0 . 
Trunk and Hip Flexion

The trunk flexion test was demonstrated by the examiner and then repeated by the subject. The subject attempted to touch the palms flat to the floor while keeping the knees either extended or hyperextended. If the subject was able to flex the trunk so that the palms are flat on the ground, then trunk flexion receives a score of 1 ; otherwise, a score of 0 was assigned.

All five components of the Beighton hypermobility test (right and left fifth fingers, right and left wrist and thumb, right and left elbows, right and left knees and trunk and hip) were measured and scored as either a 0 or a 1 . The scores were totaled for each subject. These composite scores were then placed into 1 of 3 categories (category $1=0$ to 2 points, category $2=$ 3 to 4 points, category $3=5$ to 9 points). Category 3 ( 5 to 9 points) was considered as having generalized laxity. $5,7,13$

Table 3. Nine-point Beighton hypermobility score.

\begin{tabular}{|l|c|c|}
\hline & Left & Right \\
\hline 1. Passively extend the $5^{\text {th }}$ metacarpophalngeal joint to $\geq 90^{\circ}$ & 1 & 1 \\
\hline 2. Oppose the thumb to the volar aspect of the ipsilateral forearm & 1 & 1 \\
\hline 3. Hyperextend the elbow $\geq 10^{\circ}$ & 1 & 1 \\
\hline 4. Hyperextend the knee $\geq 10^{\circ}$ & 1 & 1 \\
\hline 5. Place hands o the floor without bending the knees & \multicolumn{2}{|c|}{1} \\
\hline Total possible score & \multicolumn{2}{|c|}{9} \\
\hline
\end{tabular}

For hip range of motion, the examiner used the $0-180^{\circ}$ notation system to the nearest whole degree. A 180-degree, transparent plastic goniometer with a scale with every degree marked was used. The patients lay on a firm treatment table. Passive range of motion (PROM) was measured on the dominant leg, only once, to avoid a treatment effect. Internal and external rotation was measured in a seated position with the hips and knees at $90^{\circ}$ of flexion. Extension was tested prone, with the examiner firmly stabilizing the sacrum. The supine position was used 
for measuring flexion, abduction and adduction. Proper pelvis stabilization was taken care of by the examiner by fixating it with the other hand. The protocol for PROM measurements included a standardized testing sequence, extremity position and the goniometer alignment for both arms with reference points inked on bony landmarks on the skin. The landmarks for flexion and extension were the greater trochanter and the lateral epicondyle of the femur and for abduction and adduction the midline of the patella. The method used for stretching the soft tissues at the end-point of motion relied on the examiner's clinical experience.

\subsubsection{Proprioception testing}

TTDPM and FS were examined in the sagittal plane and the frontal plane. JPS was tested in the sagittal, frontal and transverse planes (Table 4). Since leg dominance appears to be an

unrelated etiologic factor for noncontact ACL injuries,${ }^{84}$ only the dominant leg was tested for proprioception. Due to the sensitivity and concentration required for the tasks, 10 minutes of rest between each proprioception test (including each plane of movement) was provided. Anthropometric measurements were taken and reflective markers were placed in preparation of the active JPS testing using 3D motion analysis. Anthropometric measurements included body weight and height, knee and ankle diameter and leg length (ASIS - medial malleolus). Reflective markers were placed bilaterally over the heel, lateral malleolus, second metatarsal head, femoral epicondyle and ASIS and PSIS. Another four markers were placed bilaterally on the lateral side of the mid-thigh and mid-calf. Joint angles of the hip were calculated using Vicon's Nexus software. 
Table 4. Testing setup

\begin{tabular}{|l|c|c|c|}
\hline & TTDPM & FS & JPS \\
\hline IR/ER & & & $X$ \\
\hline FL/EXT & $X$ & $X$ & $X(f l e x)$ \\
\hline ABD/ADD & $\mathrm{X}$ & $\mathrm{X}$ & $\mathrm{X}$ \\
\hline
\end{tabular}

\subsubsection{Joint position sense in transverse plane (active)}

The custom built device was used for active JPS (Figure 2). Prior to testing full ROM was measured. Subjects were tested at their maximum external and internal rotation minus 10\% of the full range of motion (ROM) respectively. Subjects were tested in a standing position and blindfolded to eliminate visual cues. The subject actively rotated the hip towards the external rotation target position. When the joint reached that target position, which was indicated by a pin in the device, the subject held that position for 5 seconds. The subject remembered this angle and the joint was returned to the starting position. The obstruction was removed and then the subject was asked to actively reproduce the test position and to stop when he or she felt the joint reached the target position (Figure 3). Five repetitions were performed. Next, the subject rotated the hip from the starting position to the target internal rotation position, the subject held that position for 5 seconds. Again, the subject remembered this angle and returned the joint into the neutral starting position. The obstruction was then removed and the subject was asked to actively reproduce the angle and stop when he or she felt the joint reached the target position (Figure 4). Five repetitions were performed for each leg and kinematics of the hip was averaged across those trials. The start and stop angles were recorded for data analysis. And the amount of discrepancy in degrees was recorded as error. 


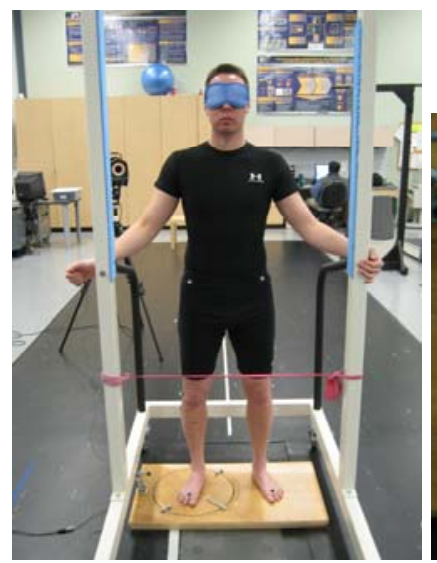

A

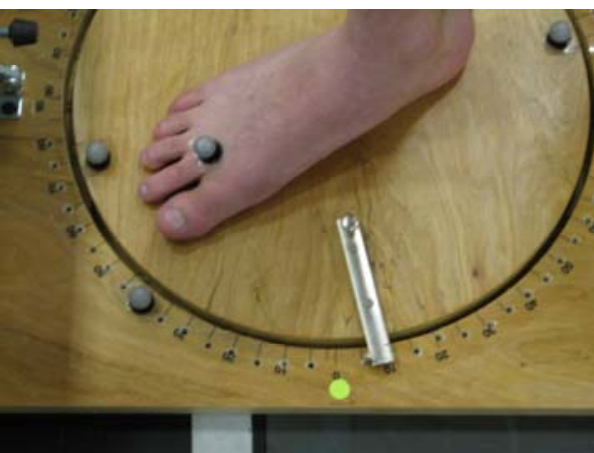

B

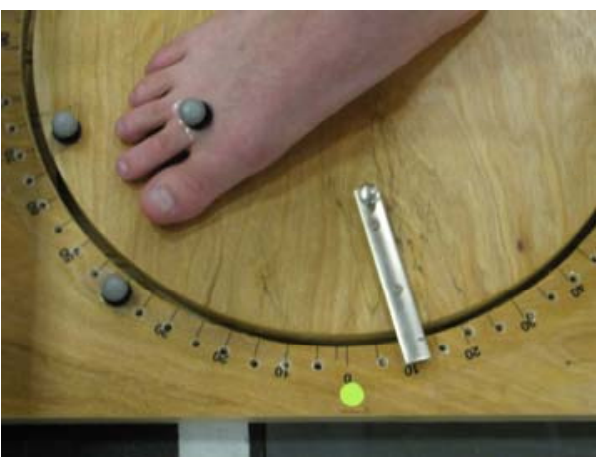

C

Figure 3. Testing set up for external rotation active JPS

A) Starting position: subject stood with the test leg on the freely rotating turntable, B) Subject rotated towards the target indicated with the pin, C) Subject reproduced the target position without the pin.

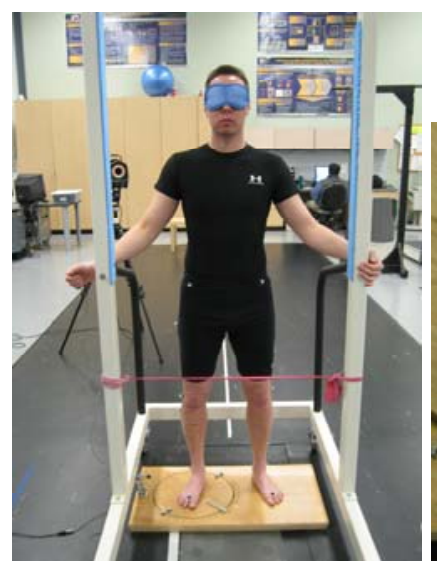

A

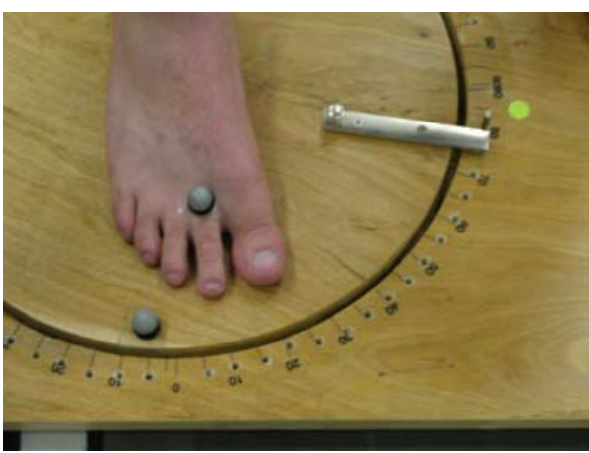

B

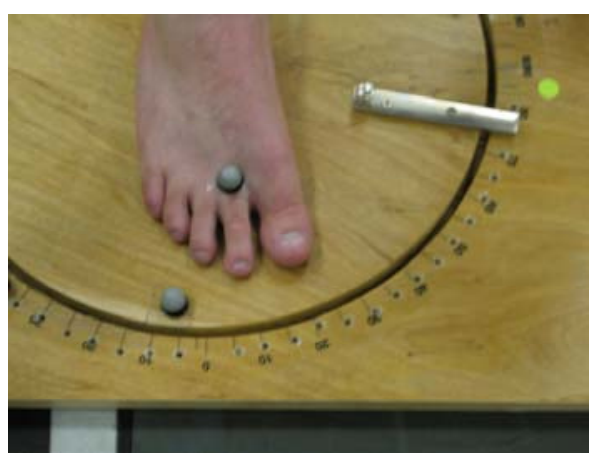

C

Figure 4. Testing set up for internal rotation active JPS

A) Starting position: subject stood with the test leg on the freely rotating turntable, B) Subject rotated towards the target indicated with the pin, C) Subject reproduced the target position without the pin. 


\subsubsection{Joint position sense in sagittal plane (active)}

Subjects were tested in a standing position and blindfolded to eliminate visual cues. The test started at neutral position ( $0^{\circ}$ in each plane) and the subject actively flexed the hip toward the flexion target position of $45^{\circ}$. When the joint reached that target position, which was be indicated by a mechanical obstruction, the subject held that position for 5 seconds. The subject remembered this angle and brought the joint actively back to the neutral starting position. Then the obstruction was removed. The subject was asked to actively reproduce the test position and to stop when he or she felt that the joint reached the position (Figure 5). Five repetitions were performed for each leg and kinematics of the hip was averaged across those trials. The start and stop angles were recorded for data analysis. And the amount of discrepancy in degrees was recorded as error.

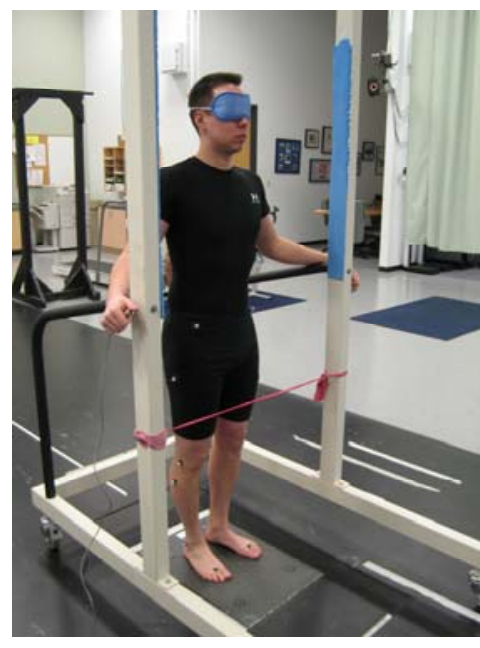

A

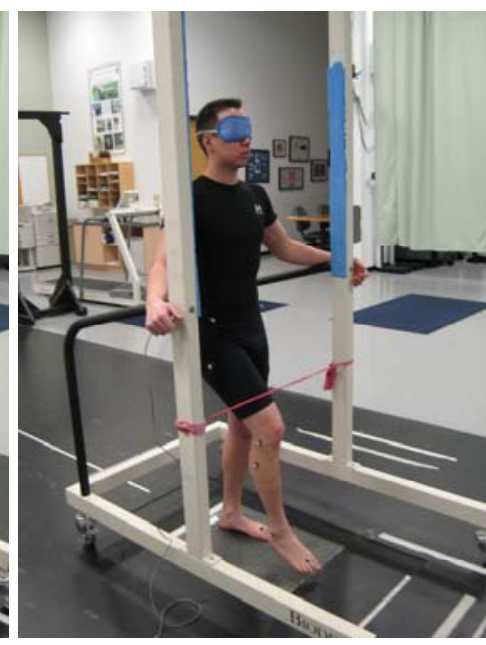

B

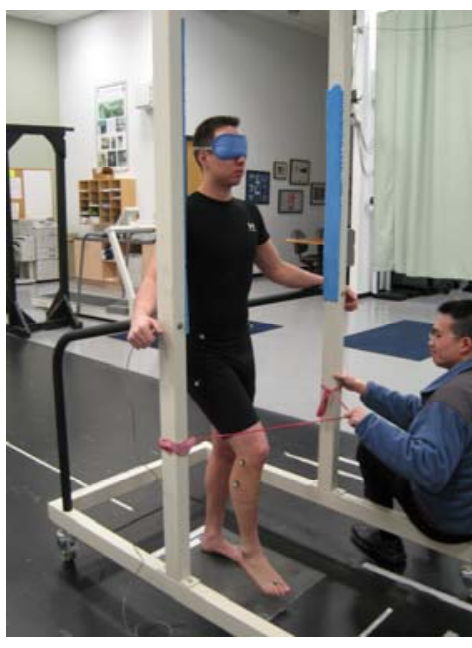

C

\section{Figure 5. Testing set up for flexion active JPS}

A) Starting position: subject stood in neutral position, B) Subject flexed the hip towards the target, C) Subject reproduced the target position. 


\subsubsection{Joint position sense in frontal plane (active)}

Subjects were tested in a standing position and blindfolded to eliminate visual cues. The test starts at the neutral position with regard to the frontal plane $\left(0^{\circ}\right.$ of abduction / adduction $)$ and the subject actively moved the leg toward the abduction target position of $15^{\circ}$. When the joint reached the target position, which was indicated by a mechanical obstruction on the ground, the subject held that position for 5 seconds. The subject remembered this angle and the joint was moved back actively to the starting position. Then the obstruction was removed. The subject reproduced the angle actively and stopped when he or she felt that the joint reached the position (Figure 6). Five repetitions were performed. Next, the subject moved the leg from the neutral starting position $15^{\circ}$ towards adduction. When the joint reached the target adduction position, the subject held that position for 5 seconds. Again, the subject remembered this angle and the joint was moved back actively into the neutral starting position. Then the obstruction was removed. The subject reproduced the angle actively and stopped when he or she felt that the joint reached the position (Figure 7). Five repetitions were performed for each leg and kinematics of the hip was averaged across those trials. The start and stop angles were recorded for data analysis. And the amount of discrepancy in degrees was recorded as error. 


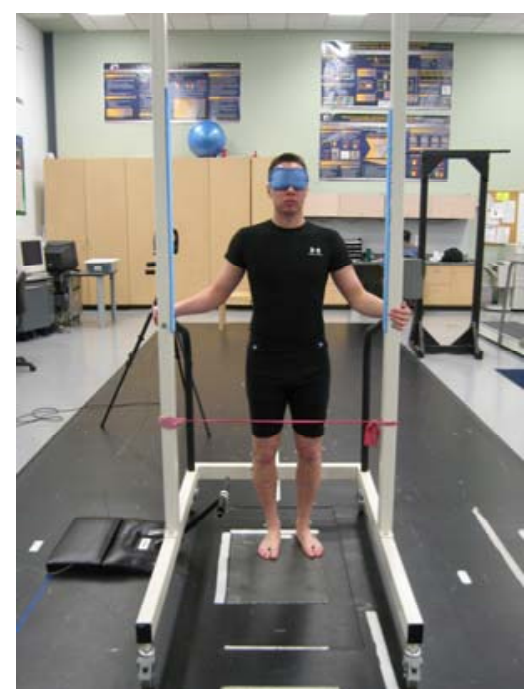

A

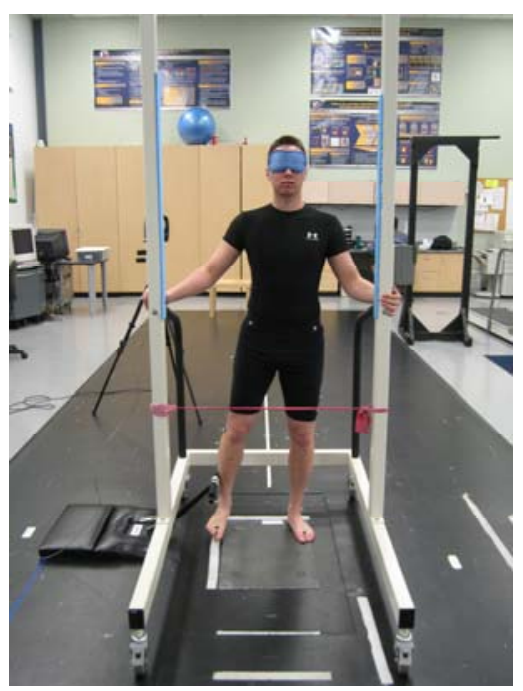

B

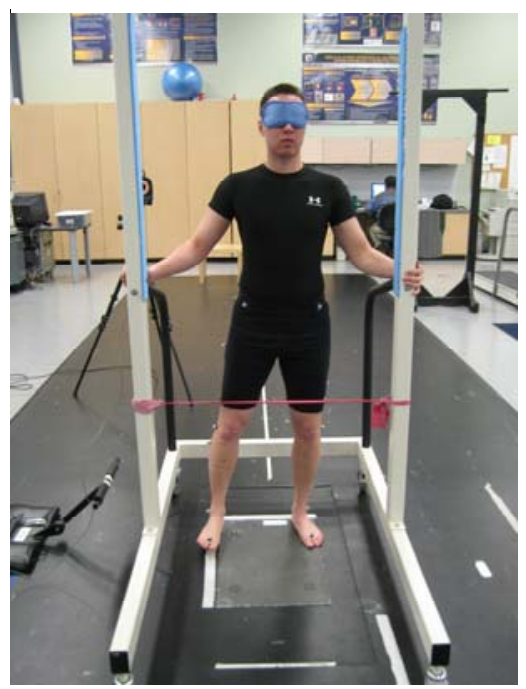

C

Figure 6. Testing set up for abduction active JPS

A) Starting position: subject stood in neutral position, B) Subject abducted the hip towards the target, C) Subject reproduced the target position.

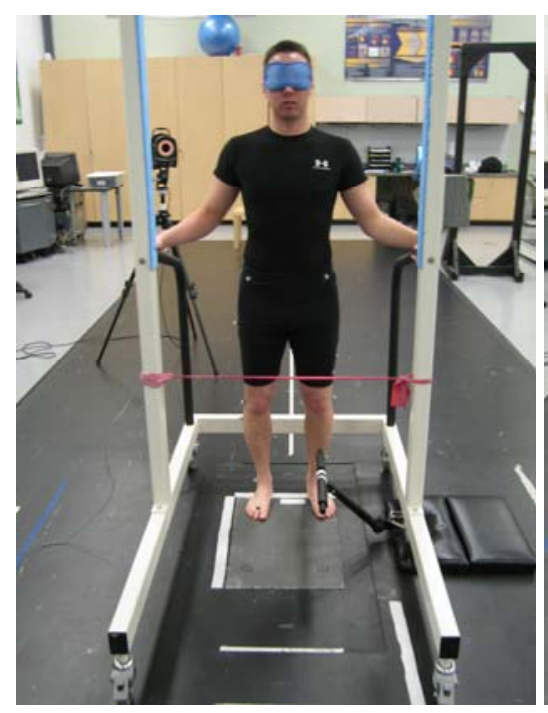

A

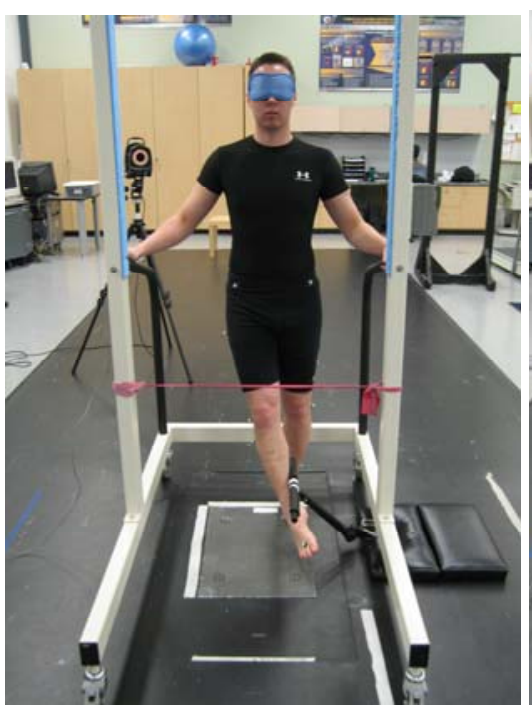

B

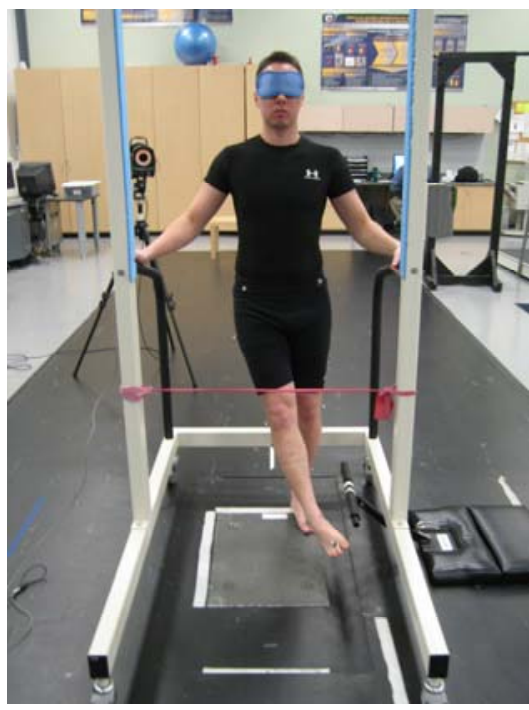

C

Figure 7. Testing set up for adduction active JPS

A) Starting position: subject stood in neutral position, B) Subject adducted the hip towards the target, C) Subject reproduced the target position. 


\subsubsection{Threshold to detect passive motion in sagittal plane}

Subjects were tested in a supine position, blindfolded and their ears covered by headphones with white noise to eliminate visual and auditory cues. The subject's contralateral thigh was securely and comfortably held with a padded strap. An inflated pneumatic sleeve was placed around the entire tested leg to minimize any tactile feedback between the dynamometer and the limb. The pneumatic sleeve was inflated to a minimal pressure (40 $\mathrm{mm} \mathrm{Hg})$ that did not disrupt normal blood flow in the lower leg. The sleeve was hooked onto the attachment (Figure 8). The test started with the hip in $45^{\circ}$ of flexion. The knee was in extension during the test. At an unannounced time ( $\sim 0-30$ seconds), the hip moved passively into either flexion or extension at a rate of $0.25 \%$ second. The subject was instructed to press a stop button as soon as he or she felt motion and was able to identify direction (either flexion or extension). The displacement between the initiation of motion and the subject's perception of motion and direction was recorded in degrees. In total, five repetitions for flexion and extension were randomly performed. If the subject pushed the stop button, and indicated the wrong direction, that trial was not counted. The start and stop angles were recorded for data analysis.

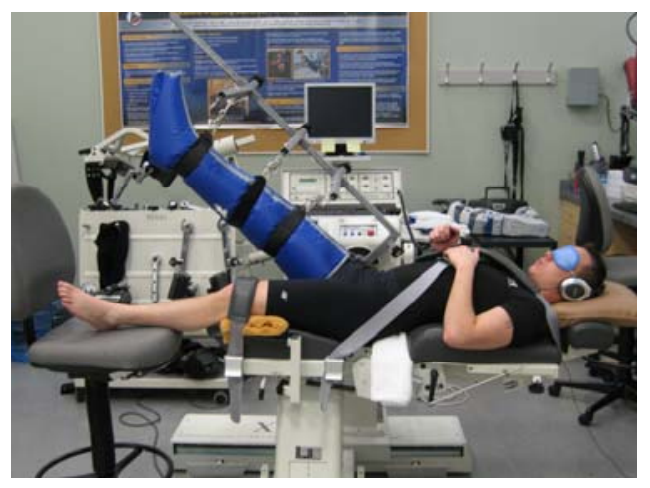

Figure 8. Testing set up for flexion / extension TTDPM 


\subsubsection{Threshold to detect passive motion in frontal plane}

Subjects were tested in a side lying position blindfolded and their ears covered by headphones with white noise to eliminate visual and auditory cues. The subject's contralateral thigh was securely and comfortably held with a padded strap. An inflated pneumatic sleeve was placed around the entire tested leg to minimize any tactile feedback between the dynamometer and the limb. The knee was in extension during the test. The pneumatic sleeve was inflated to a minimal pressure $(40 \mathrm{~mm} \mathrm{Hg})$ that did not disrupt normal blood flow in the lower leg. The sleeve was hooked onto the attachment (Figure 9). At an unannounced time ( $\sim 0-30$ seconds), the test started with the hip in $15^{\circ}$ of abduction and then the hip passively moved into either abduction or adduction at a rate of $0.25 \%$ second. The subject was instructed to press a stop button as soon as he or she felt motion and could identify direction (either flexion or extension). The displacement between the initiation of motion and the subject's perception of motion and direction was recorded in degrees. In total, five repetitions for abduction and adduction were randomly performed. If the subject pushed the stop button, and indicated the wrong direction, that trial was counted. The start and stop angles were recorded for data analysis.

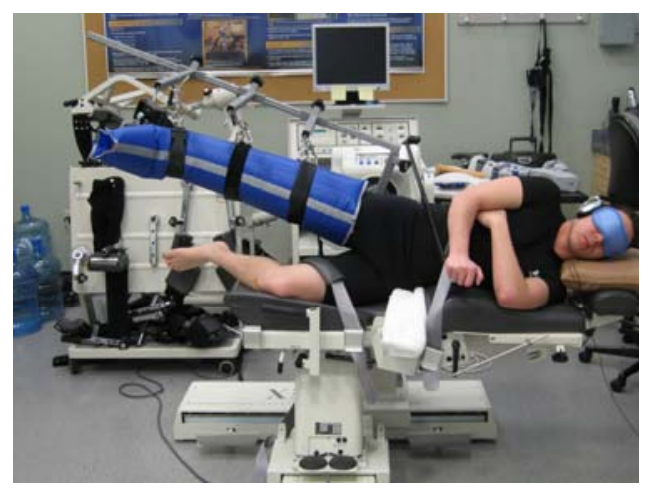

Figure 9. Testing set up for abduction / adduction TTDPM 


\subsubsection{Force sense in sagittal plane}

For this test, the subjects were tested in a supine position and the test starts in $45^{\circ}$ of hip flexion. The subject's ipsilateral thigh was securely and comfortably held with a padded strap. The attachment was secured just above the knee. The lower leg was hanging freely without any support (Figure 10). The subject extended and flexed the hip with as much force as possible for five seconds. The three repetitions of maximum voluntary isometric extension and flexion were carried out with an interval of 10 seconds. The maximum torques for three trials were averaged as the mean MVIC (maximum voluntary isometric contraction). Next, both extension and flexion force sense were tested. The subject extended and flexed the hip keeping the target torque (25\% MVIC) while watching the monitor and remembering that force for five seconds. After the five second rest interval, the subject reproduced the target torque for five seconds without visual feedback from the monitor. Five repetitions each for extension and flexion were performed on each leg. Both visual and non-visual trials were recorded and averaged. The differences between the visual and non-visual trials were used as force sense error (in Newton-Meters).

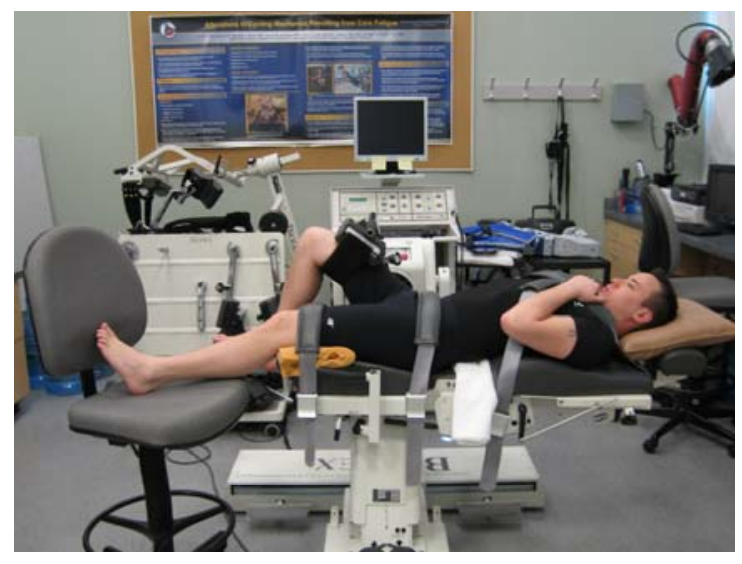

Figure 10. Testing set up for flexion / extension FS 


\subsubsection{Force sense in frontal plane}

Subjects were tested in a side lying position. The subject's ipsilateral thigh was securely held with the strap. The angle of the hip was held at $15^{\circ}$ of abduction during the test. The attachment was securely and comfortably held with a padded strap (Figure 11). The subject abducted and adducted the hip with as much force as possible. The three repetitions of maximum voluntary isometric abduction and adduction for five seconds were carried out with a 10 second rest interval. The maximum torques for three trials were averaged as the mean MVIC. Next, the abduction and adduction force sense was tested. The subject abducted and adducted the hip keeping the target torque (25\% MVIC) while watching the computer monitor and remembering that force for five seconds. After the five second rest interval, the subject reproduced the target torque for five seconds without visual feedback from the monitor. Five repetitions each for abduction and adduction were performed on each leg. Both visual and non-visual trials were recorded and averaged. The differences between the visual and non-visual trials were used as force sense error (in Newton-Meters).

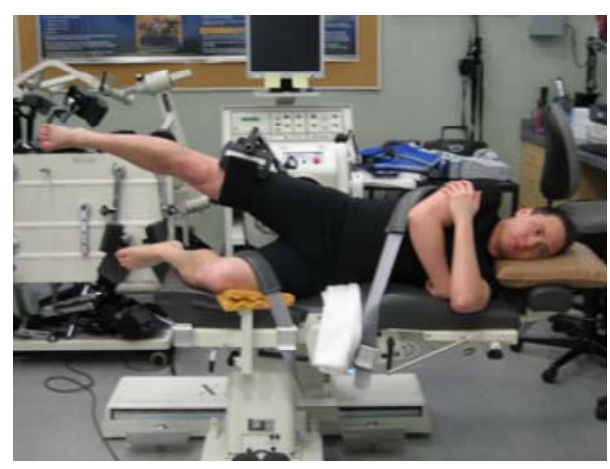

Figure 11. Testing set up for abduction / adduction FS 


\subsection{DATA REDUCTION AND ANALYSIS}

Mean and standard deviations of all proprioception tests were recorded. Error scores were calculated as the absolute difference between the reference and reproduction values for all modalities. The variables of interests were as follows:

1. For active JPS, hip joint kinematics of the dominant limb were evaluated at the starting and end point of motion, as defined by the amount of degrees mentioned in sections 3.5.2.5, 3.5.2.6 and 3.5.2.7. Joint kinematic data were exported to Matlab (release 7.0.4, The MathWorks, Natick, Mass) for identification of the variables of interest: active JPS absolute error (in ${ }^{\circ}$ ) in the sagittal (flexion only), frontal (abduction and adduction) and transverse planes (internal and external rotation). Five trials were averaged.

2. For TTDPM, raw torque data was exported utilizing the Biodex Research Toolkit. Five TTDPM trials were averaged in each plane to get the variables of interest: TTDPM error (in ${ }^{\circ}$ ) in the sagittal (towards flexion and towards extension) and frontal planes (towards abduction and towards adduction)

3. For FS, the last three seconds of each trial were averaged. The difference between the eyes open and eyes closed trials was calculated and gave the variable of interest: FS absolute error (in Newton-meters) in the sagittal (flexion and extension) and frontal planes (abduction and adduction). Five trials were averaged. 
Intra-class correlation (ICC) and standard error of measurement (SEM) were used to assess the inter- and intrareliability and accuracy of the proprioception tests. SPSS 14.0 (SPSS Inc., Chicago IL) were used to calculate the ICC values. Model $(3, \mathrm{k})$ was used for intrasession ICC and model $(3, \mathrm{k})$ for the intersession ICC. In this study, values above 0.75 are indicative of good reliability and below 0.75 poor to moderate reliability. ${ }^{106}$ 


\subsection{RESULTS}

\subsubsection{Joint position sense}

The means and the standard deviations for absolute errors are presented in Table 5. The reliability and precision results for active joint position sense are presented in Table 6. As can be seen in Table 6, the intrasession ICC ranges from 0.159 for internal rotation to 0.319 for external rotation. The intersession ICC ranges from -0.079 for internal rotation to 0.753 for adduction. The intrasession SEM numbers range from 0.717 for adduction to 1.931 for flexion, while intersession SEM ranges from 0.248 to 1.246 .

Table 5. Means and standard deviations (SD) of absolute errors for joint position sense

\begin{tabular}{|l|c|c|}
\hline & Day 1 & Day 2 \\
\cline { 2 - 3 } & Mean absolute error (SD) & Mean absolute error (SD) \\
\hline ER & $2.987(2.340)$ & $2.357(1.691)$ \\
\hline IR & $2.547(2.097)$ & $2.360(1.789)$ \\
\hline FLEX & $2.822(2.178)$ & $2.841(2.246)$ \\
\hline ABD & $2.046(1.717)$ & $2.205(2.035)$ \\
\hline ADD & $0.942(0.802)$ & $0.903(0.780)$ \\
\hline
\end{tabular}


Table 6. Reliability and precision for joint position sense

\begin{tabular}{|c|c|c|c|c|c|c|c|c|}
\hline & $\begin{array}{c}\text { Intra ICC } \\
\text { Day } 1\end{array}$ & $\begin{array}{c}\text { Intra ICC } \\
\text { Day } 2\end{array}$ & $\begin{array}{c}\text { Intra ICC } \\
\text { Average } \\
\text { Day } 1 \& 2\end{array}$ & $\begin{array}{c}\text { Intra SEM } \\
\text { Day } 1\left(^{\circ}\right)\end{array}$ & $\begin{array}{c}\text { Intra SEM } \\
\text { Day } 2\left({ }^{\circ}\right)\end{array}$ & $\begin{array}{c}\text { Intra SEM } \\
\text { Average Day } \\
1 \& 2\left(^{\circ}\right)\end{array}$ & $\begin{array}{l}\text { Inter } \\
\text { ICC }\end{array}$ & $\begin{array}{c}\text { Inter } \\
\text { SEM ( }\left(^{\circ}\right)\end{array}$ \\
\hline ER & 0.339 & 0.299 & 0.319 & 1.870 & 1.423 & 1.647 & 0.628 & 0.854 \\
\hline IR & 0.328 & -0.010 & 0.159 & 1.721 & 1.809 & 1.765 & -0.079 & 1.246 \\
\hline FLEX & 0.179 & 0.279 & 0.229 & 1.993 & 1.868 & 1.931 & 0.737 & 0.718 \\
\hline ABD & 0.105 & 0.494 & 0.300 & 1.608 & 1.494 & 1.551 & 0.486 & 0.932 \\
\hline ADD & 0.311 & 0.076 & 0.194 & 0.664 & 0.769 & 0.717 & 0.753 & 0.248 \\
\hline
\end{tabular}

\subsubsection{Threshold to detect passive motion}

The means and the standard deviations of the absolute errors are presented in Table 7. The reliability and precision results for threshold to detect passive motion are presented in Table 8. As can be seen in Table 8, the intrasession ICC ranges from moderate ( 0.540 for extension) to good ( 0.825 for abduction). The intersession ICC shows good results, ranging from 0.777 for extension to 0.906 for abduction. The intrasession SEM numbers are slightly higher (from 0.219 to 0.310 ) than the intersession SEM number (ranging from 0.143 for flexion to 0.195 for extension).

Table 7. Means and standard deviations (SD) of absolute errors for threshold to detect passive motion

\begin{tabular}{|l|c|c|}
\hline & Day 1 & Day 2 \\
\cline { 2 - 3 } & Mean absolute error (SD) & Mean absolute error (SD) \\
\hline FLEX & $0.544(0.351)$ & $0.542(0.429)$ \\
\hline EXT & $0.641(0.398)$ & $0.710(0.573)$ \\
\hline ABD & $0.626(0.672)$ & $0.606(0.554)$ \\
\hline ADD & $0.719(0.570)$ & $0.700(0.473)$ \\
\hline
\end{tabular}


Table 8. Reliability and precision for threshold to detect passive motion

\begin{tabular}{|c|c|c|c|c|c|c|c|c|}
\hline & $\begin{array}{c}\text { Intra ICC } \\
\text { Day } 1\end{array}$ & $\begin{array}{c}\text { Intra ICC } \\
\text { Day } 2\end{array}$ & $\begin{array}{l}\text { Intra ICC } \\
\text { Average } \\
\text { Dav } 1 \& 2\end{array}$ & $\begin{array}{c}\text { Intra SEM } \\
\text { Day } 1\left(^{\circ}\right)\end{array}$ & $\begin{array}{c}\text { Intra SEM } \\
\text { Day } 2\left(^{\circ}\right)\end{array}$ & $\begin{array}{c}\text { Intra SEM } \\
\text { Average Day } \\
1 \text { \& } 2\left({ }^{\circ}\right)\end{array}$ & $\begin{array}{l}\text { Inter } \\
\text { ICC }\end{array}$ & $\begin{array}{c}\text { Inter } \\
\text { SEM }\left({ }^{\circ}\right)\end{array}$ \\
\hline FLEX & 0.482 & 0.723 & 0.603 & 0.253 & 0.185 & 0.219 & 0.810 & 0.143 \\
\hline EXT & 0.355 & 0.724 & 0.540 & 0.320 & 0.301 & 0.310 & 0.777 & 0.195 \\
\hline ABD & 0.825 & 0.825 & 0.825 & 0.281 & 0.232 & 0.256 & 0.906 & 0.176 \\
\hline ADD & 0.822 & 0.707 & 0.765 & 0.240 & 0.292 & 0.266 & 0.893 & 0.144 \\
\hline
\end{tabular}

\subsubsection{Force sense}

The means and the standard deviations of the absolute errors are presented in Table 9. The reliability and precision results for force sense are presented in Table 10. As can be seen in Table 10, the intrasession ICC ranges from 0.030 (abduction) to 0.372 (extension). The intersession ICC ranged from 0.171 and 0.764 respectively. For the intrasession SEM, the data ranged from 2.405 (adduction) to 3.019 (flexion). The intersession SEM came out to be lower: from 0.923 (flexion) to 1.664 (adduction).

Table 9. Means and standard deviations (SD) of absolute errors for force sense

\begin{tabular}{|l|c|c|}
\hline & Day 1 & Day 2 \\
\hline & Mean absolute error (SD) & Mean absolute error (SD) \\
\hline FLEX & $3.9(3.7)$ & $3.4(2.9)$ \\
\hline EXT & $3.6(3.6)$ & $4.7(3.5)$ \\
\hline ABD & $3.8(3.0)$ & $3.5(2.7)$ \\
\hline ADD & $2.7(2.1)$ & $3.5(3.9)$ \\
\hline
\end{tabular}


Table 10. Reliability and precision for force sense

\begin{tabular}{|l|c|c|c|c|c|c|c|c|}
\hline & $\begin{array}{c}\text { Intra ICC } \\
\text { Day 1 }\end{array}$ & $\begin{array}{c}\text { Intra ICC } \\
\text { Day 2 }\end{array}$ & $\begin{array}{c}\text { Intra ICC } \\
\text { Average } \\
\text { Day 1 \& 2 }\end{array}$ & $\begin{array}{c}\text { Intra SEM } \\
\text { Day 1 (Nm) }\end{array}$ & $\begin{array}{c}\text { Intra SEM } \\
\text { Day 2 (Nm) }\end{array}$ & $\begin{array}{c}\text { Intra SEM } \\
\text { Average Day } \\
\text { 1 \& 2 (Nm) }\end{array}$ & $\begin{array}{c}\text { Inter } \\
\text { ICC }\end{array}$ & $\begin{array}{c}\text { Inter SEM } \\
\text { (Nm) }\end{array}$ \\
\hline FLEX & 0.123 & 0.213 & $\mathbf{0 . 1 6 8}$ & 3.465 & 2.573 & $\mathbf{3 . 0 1 9}$ & $\mathbf{0 . 7 6 4}$ & $\mathbf{0 . 9 2 3}$ \\
\hline EXT & 0.394 & 0.350 & $\mathbf{0 . 3 7 2}$ & 2.802 & 2.822 & 2.812 & $\mathbf{0 . 6 3 9}$ & $\mathbf{1 . 5 0 2}$ \\
\hline ABD & 0.026 & 0.034 & $\mathbf{0 . 0 3 0}$ & 2.961 & 2.654 & $\mathbf{2 . 8 0 7}$ & $\mathbf{0 . 1 7 1}$ & $\mathbf{1 . 1 8 4}$ \\
\hline ADD & 0.299 & 0.387 & $\mathbf{0 . 3 4 4}$ & 1.757 & 3.053 & $\mathbf{2 . 4 0 5}$ & $\mathbf{0 . 4 2 8}$ & $\mathbf{1 . 6 6 4}$ \\
\hline
\end{tabular}

\subsubsection{Hip ROM and generalized laxity}

Hip range of motion is presented in Table 11. The results for generalized laxity are presented in Table 12. The results have been graded into 1 of 3 categories (category $1=0$ to 2 points, category $2=3$ to 4 points, category $3=5$ to 9 points). Category 3 was considered as having generalized laxity. ${ }^{5,13}$ Only one subject belonged to this category.

Table 11. Hip range of motion dominant leg (average of day 1)

\begin{tabular}{|l|c|}
\hline Direction & Degrees (SD) \\
\hline IR & $44.50(6.87)$ \\
\hline ER & $46.55(8.94)$ \\
\hline ABD & $46.90(6.30)$ \\
\hline ADD & $16.70(3.37)$ \\
\hline FLEX & $125.20(10.14)$ \\
\hline EXT & $22.50(4.98)$ \\
\hline
\end{tabular}

Table 12. Generalized laxity results

\begin{tabular}{|c|c|}
\hline Category & Number of subjects \\
\hline 1 & 13 \\
\hline 2 & 6 \\
\hline 3 & 1 \\
\hline
\end{tabular}


A secondary analysis was performed to determine if between day differences can be predicted by hip ROM and / or generalized laxity. The results of the correlation analysis on excessive hip ROM, generalized laxity and the between day differences for all the dependent variables are attached to this document in Appendix H. Because reliability analyses between day one and day two showed good intersession ICC results (Appendix I), only the ROM of day 1 was used for the correlation analyses.

For JPS, the correlation analysis revealed that between day differences in abduction JPS were correlated with adduction ROM $(\mathrm{r}=-0.394, P=0.043)$. Also, greater external rotation ROM $(\mathrm{r}=0.413, P=0.035)$ and greater extension ROM $(\mathrm{r}=0.594, P=0.003)$ was correlated with the between day differences in adduction JPS. For FS, adduction ROM $(\mathrm{r}=-0.161, P=$ $0.002)$, flexion ROM $(\mathrm{r}=-0.572, P=0.004)$ and extension $\mathrm{ROM}(\mathrm{r}=-0.557, P=0.005)$ correlated with the between day differences in extension FS. Also, between day differences in abduction FS was correlated with external rotation ROM $(\mathrm{r}=0.566, P=0.005)$ and extension ROM $(r=0.421, P=0.032)$. For TTDPM, adduction ROM $(r=0.380, P=0.049)$ and extension ROM ( $\mathrm{r}=0.465, P=0.019)$ correlated with the between day differences in flexion TTDPM. Between day differences for extension TTDPM correlated with flexion ROM $(r=0.496, P=$ $0.013)$ and extension ROM $(r=0.426, P=0.031)$. Between day differences for abduction TTDPM correlated with abduction ROM $(r=-0.484, P=0.015)$ and adduction ROM $(r=0.391$, $P=0.044)$. Lastly, abduction ROM was also correlated with the between day differences for adduction TTDPM $(\mathrm{r}=-0.389, P=0.045)$. 


\subsection{DISCUSSION}

\subsection{RELIABILITY OF HIP PROPRIOCEPTION MEASURES}

The purpose of this study was to establish the intersession and intrasession reliability and precision for TTDPM, FS and active JPS tests of the hip in healthy individuals with no previous hip injuries or surgeries. The first specific aim was to establish the intra- and intersession reliability and precision of measuring TTDPM and FS of the hip. The results for TTDPM and FS will be discussed in paragraphs 5.1.2 and 5.1.3. The second specific aim was to establish the intra- and intersession reliability and precision for measuring active JPS of the hip. The results of active JPS will be discussed in 5.1.1.

\subsubsection{Joint position sense}

The majority of joint position sense measurements did not show good reliability. ${ }^{106}$ However, an intersession ICC of 0.753 for adduction suggests that this test could be used to compare presession with post-session conditions. For internal rotation, the intrasession ICC on day two (0.010) and the intersession ICC (-0.079) cannot be considered valid and may be due to nonsignificant between-subject variance.

Joint position sense at the shoulder has been reported to have good intraclass correlation

coefficients, ${ }^{20} 0.981$ with the joint in a testing position of $90 \%$ of IR ROM and 0.984 with the 
joint at $90 \%$ of ER ROM. Others have reported an intrasession ICC (SEM) of $0.71 \pm 0.27$ $\left(1.45 \pm 0.63^{\circ}\right)$ and an intersession ICC (SEM) of $0.36 \pm 0.31\left(1.56 \pm 0.68^{\circ}\right)$ for flexion and extension of the knee. ${ }^{98}$ For knee rotation, the intrasession ICC (SEM) was $0.64 \pm 0.20\left(1.48 \pm 0.67^{\circ}\right)$ and the intersession ICC (SEM) ranges were $0.49 \pm 0.19\left(0.95 \pm 0.28^{\circ}\right) .{ }^{99}$

Potential reasons for the poor results in this study may be related to the difficulty in task performance. Considering individual subject responses and the nature of the task (non-weight bearing for flexion, abduction and adduction) it seems replicating the position requested was difficult. First, testing in open kinetic chain position could have potentially reduced sensory input from the articular mechanoreceptors. With limited axial pressure in the open kinetic chain position could result in reduced activation of the deep mechanoreceptors in the labrum complex. ${ }^{109}$ So during these three tasks there was potentially limited afferent input for the subjects to remember the position. Second, flexion, abduction and adduction were not tested at end ROM, potentially leading to minimal stimulus for the mechanoreceptors and again reduced sensory feedback. Active JPS for external and internal rotation were tested in a weight bearing position but most of the weight was on the non-tested leg also potentially resulting in diminished activation of the deep articular mechanoreceptors for the test leg. Even though tested towards end ROM, it could be that the mechanoreceptors were not optimally triggered.

In addition, it was apparent that subjects demonstrated different strategies for JPS that could easily affect the results. Some subjects performed a quick repositioning without any hesitation and pressed the switch, while others stopped near their final target and 'wiggled' back and forth to fine tune their position prior to pressing the switch. Since the exact strategy to be performed was not outlined during pre-test instructions, the variations in strategy were tolerated. However, quick repositioning could have resulted in more error between the trials with and 
without the target. A suggestion for future research would be to alter the verbal cues and strictly state that all subjects should focus at the target position before pressing the switch. This potentially will make testing across subjects more consistent.

Great effort was made to ensure the subjects comfort and safety. However, when testing in a single legged standing position with the eyes blindfolded, a subject had to focus on maintaining balance. This could have affected their ability to solely focus on the tested hip. On the other side, the advantage of testing in a standing position is that it better reflects joint positions during daily activities and sports. Improvements in active JPS procedures may include testing abduction, adduction, flexion and extension using the Biodex System 3 Multi-Joint Testing and Rehabilitation System (Biodex Medical Inc, Shirley, NY). Both procedures (standing versus lying down) will be open kinetic chain, so it might be worthwhile to consider testing in a supine or side lying position instead of a standing position. The advantage of testing in a supine or side lying position is that the subject will have more support and will be better able to focus on the hip joint. No focus will be necessary to keep balance. Also, when using the Biodex System, the leg will be guided, as the leg will be attached to the dynamometer. This will in all likelihood create more consistency across trials. In summary, using the Biodex System will minimize confounding factors affecting the test procedures.

\subsubsection{Threshold to detect passive motion}

The threshold to detect passive motion measurements showed good reliability. ${ }^{106}$ Previous research has also presented good reliability and precision TTDPM data. For the knee, TTDPM has been shown to have good test-retest reliability for the flexion and extension directions ${ }^{74,98}$ and also for rotational directions. ${ }^{99}$ Specifically, the intrasession ICC (SEM) for 
flexion and extension was $0.86 \pm 0.07\left(0.25 \pm 0.07^{\circ}\right)$ and the intersession ICC (SEM) was $0.80 \pm 0.11\left(0.26 \pm 0.09^{\circ}\right) .{ }^{98}$ The intrasession ICC (SEM) for knee internal and external rotation was reported as $0.75 \pm 0.06\left(0.33 \pm 0.05^{\circ}\right)$ and the intersession ICC (SEM) as $0.84 \pm 0.09$ $\left(0.23 \pm 0.09^{\circ}\right) .{ }^{99}$

This is the first study showing that hip TTDPM measurements are reliable and precise and could therefore be used in future research projects.

\subsubsection{Force sense}

The majority of force sense measurements did not show good reliability, ${ }^{106}$ but an intersession ICC of 0.764 for flexion suggests that this test could be implemented when comparing pre-session with post-session conditions.

Force sense has been reported to have good ICC values in the shoulder, 0.981 with the joint in $90 \%$ of IR ROM and 0.978 with the joint at $90 \%$ of ER ROM. ${ }^{20}$ A study evaluating force sense reliability and precision at the ankle joint reported an ICC and SEM of 0.84 to 0.89 and 0.97 to $2.42 \mathrm{~N}$, respectively. ${ }^{19}$ For knee flexion and extension, an intrasession and intersession ICC (SEM) of $0.82 \pm 0.10(1.06 \pm 0.51 \mathrm{Nm})$ and $0.79 \pm 0.18(0.94 \pm 0.68 \mathrm{Nm})$ respectively have been reported. ${ }^{99}$ For knee rotation, the intrasession ICC (SEM) was $0.80 \pm 0.08(0.36 \pm 0.10 \mathrm{Nm})$ and the intersession ICC $(\mathrm{SEM})$ was $0.49 \pm 0.19\left(0.95 \pm 0.28^{\circ}\right) .{ }^{99}$

Reasons for poor reliability found in this study are likely multi-factorial. Force sense testing toward abduction did show the worst reliability. The intrasession ICC was 0.030 and the intersession ICC was 0.171. Based on observations and subject feedback, a potential reason for this could be that it was hard to maintain the required side lying posture with the hip in neutral position and still produced the force. When keeping the test position, the tensor fasciae latae, the 
gluteus medius and the gluteus minimus were the intended muscles to be tested. Subjects had the tendency to externally rotate the hip to be able to recruit more muscle fibers, particularly from the hip flexors. Clear instructions however were given to solely abduct the hip, which possibly resulted in performing a task that was hard to perform.

A second factor could be related to giving verbal cues. Despite best efforts to be consistent across all subjects and informing the subjects that they should focus on moving the hip and eliminate using other body parts to generate force, observation during testing revealed that subjects adopted different strategies. For hip flexion, some subjects only flexed the leg being tested. This is the preferred strategy. Other subjects compensated by extending the contralateral leg simultaneously while flexing the test leg. Obviously, as different muscles will be recruited, this will generate different forces and torques. A suggestion for future research would be to alter the verbal cues and strictly state whether subjects are or are not allowed to incorporate the contralateral leg during testing. Also, future research should focus on trying to better isolate the hip. Even though this was probably the best option possible (standing would allow for even more additional movements) it is recommended to continue looking for ways to strap and position the subjects securely. As FS testing was done at the end of the whole protocol, attention could have been an issue. Because concentration is an important issue in proprioception testing, it is recommended for future research to either perform the different testing modalities in different sessions or to give the subjects a larger break between sessions.

\subsubsection{Hip ROM and generalized laxity}

Hip ROM and generalized laxity measurements were taken in order to determine if they affected the reliability of the independent proprioception variables measured. The goal was to 
determine if between day differences were correlated to hip ROM and / or generalized laxity. A correlation analysis was performed on excessive hip ROM and / or generalized laxity and the between day differences for all the dependent variables.

No clear pattern existed for the correlation analyses results on JPS and FS. Often times, the association between the two variables was not in the same plane, making it very hard to explain the results. Because no clear pattern could be found and because the relationships did appear across various planes, it could be that these relationships occurred by chance.

Non-normalized test positions relative to an individual's available hip ROM appears to affect consistency of testing between days. Standardizing to a set test position in subjects and not accounting for available hip ROM for the individual may have contributed to testing near midrange in some subjects and testing near end-range in others. For TTDPM, it seems that there was a trend that greater ROM in a certain plane was related to the between day differences in that same plane. Greater flexion ROM was correlated to the between day differences in extension TTDPM $(r=0.496, P=0.013)$ and greater extension ROM was correlated to the between day differences in flexion $(\mathrm{r}=0.465, P=0.019)$ and extension TTDPM $(\mathrm{r}=0.426, P=0.031)$. In addition, greater abduction ROM was correlated to the between day differences in abduction $(\mathrm{r}=$ $-0.484, P=0.015)$ and adduction TTDPM $(r=-0.389, P=0.045)$ and greater adduction ROM was correlated to the between day differences in abduction TTDPM $(\mathrm{r}=0.391, P=0.044)$. The testing positions for both sagittal and frontal planes were set at $45^{\circ}$ flexion and $15^{\circ}$ abduction, respectively. In cases where testing near end ROM, potential triggering of mechanoreceptors could have been more intense, and therefore provide greater sensory feedback. Whereas testing near mid ROM, potential triggering of mechanoreceptors could have been less intense, and therefore provide less sensory feedback. For those who had greater ROM, testing could very well 
been more difficult near mid ROM, resulting in less consistent results between days. When looking at the current results, more difficulty in testing was generally correlated to the differences between days of TTDPM testing. Only greater abduction ROM was correlated with a smaller between day difference in abduction and adduction TTDPM. It is hard to distinguish whether this had occurred by chance and further investigation is necessary to explain these relationships. It needs to be addressed that the correlations found in this study are mainly in the range from 0.25 to 0.50 , suggesting a fair degree of relationship. ${ }^{106}$ A great percentage of the between day differences should therefore still be explained by other factors. Considering the relationship found between hip ROM and TTDPM testing, and in order to account for consistency across subjects regarding the amount of sensory input from the mechanoreceptors, it is of value for future research to consider testing according to a subject's available hip ROM.

\subsection{STUDY LIMITATIONS}

\subsubsection{Instrumentation}

The proprioception methodology applied to the hip in this study was new compared to other research studies. ${ }^{52,90,101,102}$ The Biodex System 3 Multi-Joint Testing and Rehabilitation System (Biodex Medical Inc, Shirley, NY) has never been used before in proprioception testing at the hip. In this study, it was used for TTDPM and FS. The development of the attachment system used for TTDPM may at least diminish the external cutaneous input thereby, improving the validity of data collection for TTDPM. However, there is still a small chance that some external input occurred. The caveat of such an attachment may be that large areas of contact in 
general may enhance proprioception consistent with the use of bracing. ${ }^{8,9,41,87,88,129}$ The large pneumatic sleeve attached to the subject's leg may therefore have provided enough external stimuli to alter the subject's natural internal proprioception through cutaneous mechanoreceptor stimulation. This issue has been documented in the literature. ${ }^{4}$ This limitation would in all likelihood not impact FS since cutaneous input would not necessarily alter the subjects' perception of voluntary force.

\subsubsection{Variability in performance}

Non-normalized test positions relative to an individual's available hip ROM potentially affected the consistency of testing between days. Variability in performance across subjects due to different available hip ROM could have contributed to poor ICC values, as joint angle is a factor that has been shown to affect the perception of movement. For the knee, it is suggested that articular mechanoreceptors are most active at the extremes of joint position, ${ }^{15,58,65}$ so it can be assumed that proprioceptive sensitivity will be higher at the ends of knee range of motion. It is also important to note that in these positions, length- and tension-detecting mechanoreceptors housed in muscles and tendons (i.e., muscle spindles and Golgi tendon organs) are also increasingly sensitized. ${ }^{103}$ When applied to the methods used for the hip in this study, $15^{\circ}$ abduction and $45^{\circ}$ flexion are not the extremes of hip ROM. However, hip abduction of $15^{\circ}$ is within the range of positions at initial contact as reported by Krosshaug et al. (from $11^{\circ} \pm 20^{\circ}$ to $\left.19^{\circ} \pm 13^{\circ}\right)^{68}$ and has been chosen to replicate the hip position at landing (eg. after a basket- or handball throw, volleyball block or header during soccer). Testing in $45^{\circ}$ of hip flexion was selected due to the constraints of participant positioning, as it was the test position in which it was possible to cover the entire leg with the pneumatic sleeve without touching the chair (which 
could give potential external sensory input). Considering the results of Krosshaug, athletes do not land in their end ROM of flexion (but anywhere from $16^{\circ} \pm 8^{\circ}$ to $37^{\circ} \pm 7^{\circ}$ ). ${ }^{68}$ Testing in $45^{\circ}$ of hip flexion might therefore better replicate the hip joint angle at landing compared to testing near end ROM.

\subsubsection{Applicability}

In this study healthy active females and males between the age of 18 and 40 were tested. This largely represents the persons who are most prone to lower extremity injury. The results could therefore only be applied to this group and should be applied to other populations with care.

In addition, due to the fact that this is a controlled laboratory study, the outcomes do not perfectly reflect the lower extremity movement patterns during actual time of injury. Although interpretation of the results is worthy, it is difficult to predict to what extent the observed proprioception capacities of the subjects in a laboratory setting exposes the athlete to increased risk of injury on the field. ${ }^{67}$ For example, for TTDPM and FS, the subjects were tested in a supine and side lying position. This is not the position at which hip injuries occur during practice or a game. ${ }^{68}$ However, testing TTDPM and FS in supine and side lying positions are the positions that could be best controlled during testing and best isolate the hip joint. This gave the best opportunity to draw conclusions exclusively about proprioception of the hip joint.

The testing procedures examined in this study represent conscious proprioception since the subject was either actively reproducing a position or force or the conscious perception of passive movement and direction was tested. Another aspect of proprioception involves the 
unconscious control and perception of movement. This aspect is more likely involved in injury since it is responsible for the immediate response to the unpredicted perturbation that can happen to the athlete during sport and the non-athlete during function. Between the initial and the reproduction trial, the subject needs to remember the target position or the force produced. Therefore, the delay before the reproduction of a position or force is functioning as a little break to memorize the requested task. This memory does not happen the same way in real time when a person has to think about placing the leg in the proper position or generating the appropriate amount of force during landing. The time to think about it is simply not available. The feedfoward and feedback mechanisms in real time do not occur at a conscious level. The methodology employed in this study can therefore not make any judgment related to unconscious control making further research necessary to address this issue.

\subsection{FUTURE RESEARCH}

The methodology employed in this study cannot make any judgment related to unconscious control making further research necessary to address this issue. Other studies have attempted to measure response rates to unexpected perturbation for indirectly examining

unconscious mechanisms of functional stability. ${ }^{95}$ Exploring the unconscious mechanisms of proprioception and dynamic joint stability may be warranted since injuries often occur when unexpected loads are imposed upon the lower extremity.

For force sense, the independent variable used in this study (the absolute difference between the eyes open and eyes closed trial) might not be the best variable for looking at muscle mechanoreceptors. Other variables should be considered. 
Future studies are warranted expanding these methodologies for the assessment of hip proprioception. It is imperative to investigate whether 'poor' hip proprioception in healthy subjects is related to decreased control of hip joint stability. Considering the coupling of segments, ${ }^{10,80,108,130}$ decreased neuromuscular and biomechanical control of the hip could place the knee in a valgus position ${ }^{72,85,133}$ and increased risk for ACL injury, ${ }^{45,47}$ as a result of increased hip adduction and hip internal rotation motions. However, this has not been studied yet. In order to gain more knowledge of the role of the hip related to lower extremity injuries and specifically the ACL injury mechanism examining proprioceptive characteristics of the hip will be useful.

Lastly, detailed descriptions on the distribution of mechanoreceptors in the capsule and ligaments (eg. iliofemoral ligament) of the human hip could not be found. There is research suggesting that the capsule does contain mechanoreceptors, ${ }^{109}$ but this statement was not well justified. This is however important as the capsule and ligaments will be more stressed during low impact activities compared to the deep articular structures (eg. acetabular labrum).

\subsection{CONCLUSIONS}

The results of this study clearly indicate that a reliable and precise method of measuring hip TTDPM towards flexion, extension, abduction and adduction has been established. This could therefore be used in future research. Further investigation is however warranted to further develop reliable and precise measurement methods for FS and active JPS measurements of the hip. 


\title{
6.0 REFERENCES
}

\author{
References
}

1. Ageberg E, Flenhagen J, Ljung J Test-retest reliability of knee kinesthesia in healthy adults. BMC Musculoskelet Disord. 2007;8:57.

2. Appelberg B, Hulliger $\mathrm{M}$, Johansson $\mathrm{H}$, Sojka $\mathrm{P}$ Actions on gamma-motoneurones elicited by electrical stimulation of group iii muscle afferent fibres in the hind limb of the cat. J Physiol. 1983;335:275-292.

3. Appelberg B, Hulliger M, Johansson H, Sojka P Fusimotor reflexes in triceps surae elicited by natural stimulation of muscle afferents from the cat ipsilateral hind limb. $J$ Physiol. 1982;329:211-229.

4. Barrett DS, Cobb AG, Bentley G Joint proprioception in normal, osteoarthritic and replaced knees. J Bone Joint Surg Br. 1991;73:53-56.

5. Beighton P, Solomon L, Soskolne CL Articular mobility in an african population. Ann Rheum Dis. 1973;32:413-418.

6. Bendjaballah MZ, Shirazi-Adl A, Zukor DJ Finite element analysis of human knee joint in varus-valgus. Clin Biomech (Bristol, Avon). 1997;12:139-148.

7. Benoit DL, Ramsey DK, Lamontagne M, Xu L, Wretenberg P, Renstrom P Effect of skin movement artifact on knee kinematics during gait and cutting motions measured in vivo. Gait Posture. 2006;24:152-164.

8. Beynnon BD, Good L, Risberg MA The effect of bracing on proprioception of knees with anterior cruciate ligament injury. J Orthop Sports Phys Ther. 2002;32:11-15.

9. Birmingham TB, Kramer JF, Inglis JT, et al. Effect of a neoprene sleeve on knee joint position sense during sitting open kinetic chain and supine closed kinetic chain tests. $\mathrm{Am}$ J Sports Med. 1998;26:562-566.

10. Bobbert MF, van Zandwijk JP Dynamics of force and muscle stimulation in human vertical jumping. Med Sci Sports Exerc. 1999;31:303-310.

11. Bonfim TR, Jansen Paccola CA, Barela JA Proprioceptive and behavior impairments in individuals with anterior cruciate ligament reconstructed knees. Arch Phys Med Rehabil. 2003;84:1217-1223.

12. Borsa PA, Lephart SM, Irrgang JJ, Safran MR, Fu FH The effects of joint position and direction of joint motion on proprioceptive sensibility in anterior cruciate ligamentdeficient athletes. Am J Sports Med. 1997;25:336-340.

13. Boyle KL, Witt $\mathrm{P}$, Riegger-Krugh $\mathrm{C}$ Intrarater and interrater reliability of the beighton and horan joint mobility index. J Athl Train. 2003;38:281-285. 
14. Brindle TJ, Uhl TL, Nitz AJ, Shapiro R The influence of external loads on movement precision during active shoulder internal rotation movements as measured by 3 indices of accuracy. J Athl Train. 2006;41:60-66.

15. Burke D, Gandevia SC, Macefield G Responses to passive movement of receptors in joint, skin and muscle of the human hand. J Physiol. 1988;402:347-361.

16. Cerulli G, Benoit DL, Lamontagne M, Caraffa A, Liti A In vivo anterior cruciate ligament strain behaviour during a rapid deceleration movement: Case report. Knee Surg Sports Traumatol Arthrosc. 2003;11:307-311.

17. Chao EY, Neluheni EV, Hsu RW, Paley D Biomechanics of malalignment. Orthop Clin North Am. 1994;25:379-386.

18. Decker M, Torry $M$, Sterett $W$ Functional adaptations affect landing performance after acl reconstruction. Biomechanics. 2000;29-40.

19. Docherty CL, Arnold BL The relationship between ankle force sense, joint reposition sense, and functional performance tests. J Athl Train. 2005;40:S90-91.

20. Dover G, Powers ME Reliability of joint position sense and force-reproduction measures during internal and external rotation of the shoulder. J Athl Train. 2003;38:304-310.

21. Drouin JM, Valovich-mcLeod TC, Shultz SJ, Gansneder BM, Perrin DH Reliability and validity of the biodex system 3 pro isokinetic dynamometer velocity, torque and position measurements. Eur J Appl Physiol. 2004;91:22-29.

22. Fellows SJ, Thilmann AF The role of joint biomechanics in determining stretch reflex latency at the normal human ankle. Exp Brain Res. 1989;77:135-139.

23. Ferris CM. Relationship of pelvis and hip neuromechanical characteristics to the knee during a stop-jump task [dissertation]. Pittsburgh: Department of Sports Medicine and Nutrition, University of Pittsburgh; 2003.

24. Fischer-Rasmussen T, Jensen PE Proprioceptive sensitivity and performance in anterior cruciate ligament-deficient knee joints. Scand J Med Sci Sports. 2000;10:85-89.

25. Fleming $\mathrm{BC}$, Beynnon $\mathrm{BD}$, Renstrom PA, et al. The strain behavior of the anterior cruciate ligament during stair climbing: An in vivo study. Arthroscopy. 1999;15:185-191.

26. Ford KR, Myer GD, Hewett TE Valgus knee motion during landing in high school female and male basketball players. Med Sci Sports Exerc. 2003;35:1745-1750.

27. Freeman MA, Wyke B Articular reflexes at the ankle joint: An electromyographic study of normal and abnormal influences of ankle-joint mechanoreceptors upon reflex activity in the leg muscles. Br J Surg. 1967;54:990-1001.

28. Freeman MA, Wyke B The innervation of the knee joint. An anatomical and histological study in the cat. $J$ Anat. 1967;101:505-532.

29. Friden T, Roberts D, Zatterstrom R, Lindstrand A, Moritz U Proprioceptive defects after an anterior cruciate ligament rupture -- the relation to associated anatomical lesions and subjective knee function. Knee Surg Sports Traumatol Arthrosc. 1999;7:226-231.

30. Gandevia SC, Burke D Does the nervous system depend on kinesthetic information to control natural limb movements? Behav Brain Sci. 1992;15:614-632.

31. Ghez C. The control of movement. In: Kandel ER, Schwartz JH, Jessell TM, eds. Principles of neural science. New York, NY: Elsevier Science; 1991:533-547.

32. Grabiner MD Bioelectric characteristics of the electromechanical delay preceding concentric contraction. Med Sci Sports Exerc. 1986;18:37-43.

33. Gregoire L, Veeger HE, Huijing PA, van Ingen Schenau GJ Role of mono- and biarticular muscles in explosive movements. Int J Sports Med. 1984;5:301-305. 
34. Grigg P Peripheral neural mechanisms in proprioception. J Sport Rehabil. 1994;3:2-17.

35. Grillner $\mathrm{S}$ The role of muscle stiffness in meeting the changing postural and locomotor requirements for force development by the ankle extensors. Acta Physiol Scand. 1972;86:92-108.

36. Grob KR, Kuster MS, Higgins SA, Lloyd DG, Yata H Lack of correlation between different measurements of proprioception in the knee. J Bone Joint Surg Br. 2002;84:614-618.

37. Hahn T, Foldspang A The q angle and sport. Scand J Med Sci Sports. 1997;7:43-48.

38. Haus J. Innervation des vorderen kreuzbandes. Munich, University of Munich; 1997.

39. He XA, Tay SSW, Ling EA Sensory nerve endings in monkey hip joint capsule: A morphological investigation. Clin Anat. 1998;11:81-85.

40. Heijne A, Fleming BC, Renstrom PA, Peura GD, Beynnon BD, Werner S Strain on the anterior cruciate ligament during closed kinetic chain exercises. Med Sci Sports Exerc. 2004:36:935-941.

41. Herrington L, Simmonds $\mathrm{C}$, Hatcher $\mathrm{J}$ The effect of a neoprene sleeve on knee joint position sense. Res Sports Med. 2005;13:37-46.

42. Hewett TE, Ford KR, Myer GD Anterior cruciate ligament injuries in female athletes: Part 2, a meta-analysis of neuromuscular interventions aimed at injury prevention. Am J Sports Med. 2006;34:490-498.

43. Hewett TE, Ford KR, Myer GD, Wanstrath K, Scheper M Gender differences in hip adduction motion and torque during a single-leg agility maneuver. J Orthop Res. 2006;24:416-421.

44. Hewett TE, Myer GD, Ford KR Anterior cruciate ligament injuries in female athletes: Part 1, mechanisms and risk factors. Am J Sports Med. 2006;34:299-311.

45. Hewett TE, Myer GD, Ford KR, et al. Biomechanical measures of neuromuscular control and valgus loading of the knee predict anterior cruciate ligament injury risk in female athletes: A prospective study. Am J Sports Med. 2005;33:492-501.

46. Hewett TE, Paterno MV, Myer GD Strategies for enhancing proprioception and neuromuscular control of the knee. Clin Orthop Relat Res. 2002;76-94.

47. Hewett TE, Zazulak BT, Myer GD, Ford KR A review of electromyographic activation levels, timing differences, and increased anterior cruciate ligament injury incidence in female athletes. Br J Sports Med. 2005;39:347-350.

48. Hogervorst T, Brand RA Mechanoreceptors in joint function. $J$ Bone Joint Surg Am. 1998;80:1365-1378.

49. Horton MG, Hall TL Quadriceps femoris muscle angle: Normal values and relationships with gender and selected skeletal measures. Phys Ther. 1989;69:897-901.

50. Hsu RW, Himeno S, Coventry MB, Chao EY Normal axial alignment of the lower extremity and load-bearing distribution at the knee. Clin Orthop Relat Res. 1990;215227.

51. Ireland ML Anterior cruciate ligament injury in female athletes: Epidemiology. J Athl Train. 1999;34:150-154.

52. Ishii $\mathrm{Y}$, Terajima $\mathrm{K}$, Terashima $\mathrm{S}$, Matsueda $\mathrm{M}$ Joint proprioception in the elderly with and without hip fracture. J Orthop Trauma. 2000;14:542-545.

53. Jerosch J, Thorwesten L, Frebel T, Linnenbecker S Influence of external stabilizing devices of the ankle on sport-specific capabilities. Knee Surg Sports Traumatol Arthrosc. 1997;5:50-57. 
54. Johansson $\mathrm{H}$ Role of knee ligaments in proprioception and regulation of muscle stiffness. J Elect Kinesiol. 1991;1:158-179.

55. Johansson H, Sjolander P. The neurophysiology of joints. In: Wright V, Radin EL, eds. Mechanics of joints: Physiology, pathophysiology and treatment. New York, NY: Marcel Dekker Inc.; 1993:243-290.

56. Johansson H, Sjolander P, Sojka P Receptors in the knee joint ligaments and their role in the biomechanics of the joint. Crit Rev Biomed Eng. 1991;18:341-368.

57. Johansson H, Sjolander P, Sojka P A sensory role for the cruciate ligaments. Clin Orthop Relat Res. 1991;161-178.

58. Jones LA Peripheral mechanisms of touch and proprioception. Can J Physiol Pharmacol. 1994;72:484-487.

59. Karanjia PN, Ferguson JH Passive joint position sense after total hip replacement surgery. Ann Neurol. 1983;13:654-657.

60. Kaufman MP, Rybicki KJ, Waldrop TG, Ordway GA Effect of ischemia on responses of group iii and iv afferents to contraction. J Appl Physiol. 1984;57:644-650.

61. Kennedy JC, Alexander IJ, Hayes KC Nerve supply of the human knee and its functional importance. Am J Sports Med. 1982;10:329-335.

62. Kibler WB, Press J, Sciascia A The role of core stability in athletic function. Sports Med. 2006;36:189-198.

63. Kim AW, Rosen AM, Brander VA, Buchanan TS Selective muscle activation following electrical stimulation of the collateral ligaments of the human knee joint. Arch Phys Med Rehabil. 1995;76:750-757.

64. Kim YT, Azuma H The nerve endings of the acetabular labrum. Clin Orthop Relat Res. 1995;176-181.

65. Krauspe R, Schmidt M, Schaible HG Sensory innervation of the anterior cruciate ligament. An electrophysiological study of the response properties of single identified mechanoreceptors in the cat. J Bone Joint Surg Am. 1992;74:390-397.

66. Krogsgaard $\mathrm{M}$, Solomonow $\mathrm{M}$ The sensory function of ligaments. $J$ Electromyogr Kinesiol. 2002;12:165.

67. Krosshaug T, Andersen TE, Olsen OE, Myklebust G, Bahr R Research approaches to describe the mechanisms of injuries in sport: Limitations and possibilities. $\mathrm{Br} J$ Sports Med. 2005;39:330-339.

68. Krosshaug T, Nakamae A, Boden BP, et al. Mechanisms of anterior cruciate ligament injury in basketball: Video analysis of 39 cases. Am J Sports Med. 2007;35:359-367.

69. Learman KE, Myers JB, Cook CE, Lephart SM, Sell TC. Treatment effects of spinal manipulation on proprioception in subjects with chronic low back pain. Pittsburgh: School School of Health and Rehabilitation Sciences University of Pittsburgh; 2007.

70. Leetun DT, Ireland ML, Willson JD, Ballantyne BT, Davis IM Core stability measures as risk factors for lower extremity injury in athletes. Med Sci Sports Exerc. 2004;36:926934.

71. Leonard CT. The neuroscience of human movement. St Louis, MO: Mosby-Year Book Inc; 1998.

72. Lephart SM, Ferris CM, Riemann BL, Myers JB, Fu FH Gender differences in strength and lower extremity kinematics during landing. Clin Orthop Relat Res. 2002;162-169.

73. Lephart SM, Fu FH. Proprioception and neuromuscular control in joint stability. Champaign, IL: Human Kinetics; 2000. 
74. Lephart SM, Kocher MS, Fu FH Proprioception following anterior cruciate ligament reconstruction. . J Sport Rehab. 1992;188-196.

75. Lephart SM, Pincivero DM, Giraldo JL, Fu FH The role of proprioception in the management and rehabilitation of athletic injuries. Am J Sports Med. 1997;25:130-137.

76. Lephart SM, Pincivero DM, Rozzi SL Proprioception of the ankle and knee. Sports Med. 1998:25:149-155.

77. Lephart SM, Warner JJP, Borsa PA Proprioception of the shoulder joint in healthy, unstable, and surgically repaired shoulders. . J Shoulder Elbow Surg. 1994;3:371-380.

78. Leunig M, Beck M, Stauffer E, Hertel R, Ganz R Free nerve endings in the ligamentum capitis femoris. Acta Orthop Scand. 2000;71:452-454.

79. Lew WD, Lewis JL, Craig EV. Stabilization by capsule, ligaments and labrum: Stability at the extremes of motion. In: Matsen FA, Fu FH, Hawkins RJ, eds. The shoulder: A balance of mobility and stability. . Rosemont, IL: American Academy of Orthopaedic Surgeons; 1993:69-89.

80. Lloyd DG, Buchanan TS, Besier TF Neuromuscular biomechanical modeling to understand knee ligament loading. Med Sci Sports Exerc. 2005;37:1939-1947.

81. Louie JK, Mote $\mathrm{CD}$, Jr. Contribution of the musculature to rotatory laxity and torsional stiffness at the knee. J Biomech. 1987;20:281-300.

82. Malinzak RA, Colby SM, Kirkendall DT, Yu B, Garrett WE A comparison of knee joint motion patterns between men and women in selected athletic tasks. Clin Biomech (Bristol, Avon). 2001;16:438-445.

83. Markolf KL, Burchfield DM, Shapiro MM, Shepard MF, Finerman GA, Slauterbeck JL Combined knee loading states that generate high anterior cruciate ligament forces. $J$ Orthop Res. 1995;13:930-935.

84. Matava MJ, Freehill AK, Grutzner S, Shannon W Limb dominance as a potential etiologic factor in noncontact anterior cruciate ligament tears. J Knee Surg. 2002;15:1116.

85. McLean SG, Huang X, van den Bogert AJ Association between lower extremity posture at contact and peak knee valgus moment during sidestepping: Implications for acl injury. Clin Biomech (Bristol, Avon). 2005;20:863-870.

86. McLean SG, Lipfert SW, van den Bogert AJ Effect of gender and defensive opponent on the biomechanics of sidestep cutting. Med Sci Sports Exerc. 2004;36:1008-1016.

87. McNair PJ, Heine PJ Trunk proprioception: Enhancement through lumbar bracing. Arch Phys Med Rehabil. 1999;80:96-99.

88. McNair PJ, Stanley SN, Strauss GR Knee bracing: Effects of proprioception. Arch Phys Med Rehabil. 1996;77:287-289.

89. McNair PJ, Wood GA, Marshall RN Stiffness of the hamstring muscles and its relationship to function in anterior cruciate ligament deficient individuals. Clin Biomech (Bristol, Avon). 1991;7:131-137.

90. Mendelsohn ME, Overend TJ, Petrella RJ Effect of rehabilitation on hip and knee proprioception in older adults after hip fracture: A pilot study. Am J Phys Med Rehabil. 2004;83:624-632.

91. Miyatsu M, Atsuta Y, Watakabe M The physiology of mechanoreceptors in the anterior cruciate ligament. An experimental study in decerebrate-spinalised animals. $J$ Bone Joint Surg Br. 1993;75:653-657.

92. Morris W. The american heritage dictionary of the english language.; 1981. 
93. Moul JL Differences in selected predictors of anterior cruciate ligament tears between male and female ncaa division i collegiate basketball players. J Athl Train. 1998;33:118121.

94. Myer GD, Ford KR, Hewett TE The effects of gender on quadriceps muscle activation strategies during a maneuver that mimics a high acl injury risk position. J Electromyogr Kinesiol. 2005;15:181-189.

95. Myers JB, Riemann BL, Ju YY, Hwang JH, McMahon PJ, Lephart SM Shoulder muscle reflex latencies under various levels of muscle contraction. Clin Orthop Relat Res. 2003;92-101.

96. Nadler SF, Malanga GA, DePrince M, Stitik TP, Feinberg JH The relationship between lower extremity injury, low back pain, and hip muscle strength in male and female collegiate athletes. Clin J Sport Med. 2000;10:89-97.

97. Nadler SF, Malanga GA, Feinberg JH, Prybicien M, Stitik TP, DePrince M Relationship between hip muscle imbalance and occurrence of low back pain in collegiate athletes: A prospective study. Am J Phys Med Rehabil. 2001;80:572-577.

98. Nagai T, Sell TC, Nakagawa T, Myers JB, Fu FH, Lephart SM. Feasibility of knee flexion/extension proprioception assessments in a clinical setting. National Athletic Trainers Association Annual Meeting. Anaheim, CA.; 2007.

99. Nagai T, Sell TC, Nakagawa T, Myers JB, Fu FH, Lephart SM. Intrasession and intersession reliability and precision of knee internal/external rotation proprioception. American College of Sports Medicine (ACSM) 54th Annual Meeting New Orleans, Louisiana; 2007.

100. Nallegowda M, Singh U, Bhan S, Wadhwa S, Handa G, Dwivedi SN Balance and gait in total hip replacement: A pilot study. Am J Phys Med Rehabil. 2003;82:669-677.

101. Oehlert $\mathrm{K}$, Hassenpflug $\mathrm{J}$ [coordinative abilities of arthroplasty patients]. Z Orthop Ihre Grenzgeb. 2004;142:679-684.

102. Pickard CM, Sullivan PE, Allison GT, Singer KP Is there a difference in hip joint position sense between young and older groups? J Gerontol A Biol Sci Med Sci. 2003;58:631-635.

103. Pincivero DM, Lephart SM, Karunakara RA Reliability and precision of isokinetic strength and muscular endurance for the quadriceps and hamstrings. Int J Sports Med. 1997; 18:113-117.

104. Pollard CD, Davis IM, Hamill J Influence of gender on hip and knee mechanics during a randomly cued cutting maneuver. Clin Biomech (Bristol, Avon). 2004;19:1022-1031.

105. Portney LG, Watkins MP. Foundations of clinical research; 2000.

106. Portney LG, Watkins MP. Foundations of clinical research--applications to practice. 2nd ed. Upper Saddle River, NJ: Prentice Hall; 2000.

107. Proske U, Gregory JE, Morgan DL, Percival P, Weerakkody NS, Canny BJ Force matching errors following eccentric exercise. Hum Mov Sci. 2004;23:365-378.

108. Putnam CA Sequential motions of body segments in striking and throwing skills: Descriptions and explanations. J Biomech. 1993;26 Suppl 1:125-135.

109. Putz R, Schrank C [anatomy of the labro-capsular complex]. Orthopade. 1998;27:675680.

110. Quatman CE, Ford KR, Myer GD, Hewett TE Maturation leads to gender differences in landing force and vertical jump performance: A longitudinal study. Am J Sports Med. 2006;34:806-813. 
111. Rack PM, Ross HF, Thilmann AF, Walters DK Reflex responses at the human ankle: The importance of tendon compliance. J Physiol. 1983;344:503-524.

112. Raunest J, Sager M, Burgener E Proprioception of the cruciate ligaments: Receptor mapping in an animal model. Arch Orthop Trauma Surg. 1998;118:159-163.

113. Riemann BL, Lephart SM The sensorimotor system, part i: The physiologic basis of functional joint stability. J Athl Train. 2002;37:71-79.

114. Riemann BL, Lephart SM The sensorimotor system, part ii: The role of proprioception in motor control and functional joint stability. J Athl Train. 2002;37:80-84.

115. Riemann BL, Myers JB, Lephart SM Sensorimotor system measurement techniques. $J$ Athl Train. 2002;37:85-98.

116. Risberg MA, Beynnon BD, Peura GD, Uh BS Proprioception after anterior cruciate ligament reconstruction with and without bracing. Knee Surg Sports Traumatol Arthrosc. 1999;7:303-309.

117. Rotto DM, Kaufman MP Effect of metabolic products of muscular contraction on discharge of group iii and iv afferents. J Appl Physiol. 1988;64:2306-2313.

118. Rozzi SL, Lephart SM, Gear WS, Fu FH Knee joint laxity and neuromuscular characteristics of male and female soccer and basketball players. Am J Sports Med. 1999;27:312-319.

119. Rybicki KJ, Waldrop TG, Kaufman MP Increasing gracilis muscle interstitial potassium concentrations stimulate group iii and iv afferents. J Appl Physiol. 1985;58:936-941.

120. Shambaugh JP, Klein A, Herbert JH Structural measures as predictors of injury basketball players. Med Sci Sports Exerc. 1991;23:522-527.

121. Shelburne KB, Pandy MG, Anderson FC, Torry MR Pattern of anterior cruciate ligament force in normal walking. J Biomech. 2004;37:797-805.

122. Shelburne KB, Pandy MG, Torry MR Comparison of shear forces and ligament loading in the healthy and acl-deficient knee during gait. J Biomech. 2004;37:313-319.

123. Sherrington CS. The integrative action of the nervous system. New York, NY; 1906 .

124. Sigward SM, Powers CM The influence of gender on knee kinematics, kinetics and muscle activation patterns during side-step cutting. Clin Biomech (Bristol, Avon). 2006;21:41-48.

125. Simonsen EB, Magnusson SP, Bencke J, et al. Can the hamstring muscles protect the anterior cruciate ligament during a side-cutting maneuver? Scand J Med Sci Sports. 2000;10:78-84.

126. Sojka P, Johansson $H$, Sjolander P, Lorentzon R, Djupsjobacka M Fusimotor neurones can be reflexly influenced by activity in receptor afferents from the posterior cruciate ligament. Brain Res. 1989;483:177-183.

127. Stratford PW, Goldsmith $\mathrm{CH}$ Use of the standard error as a reliability index of interest: An applied example using elbow flexor strength data. Phys Ther. 1997;77:745-750.

128. Thijs Y, Van Tiggelen D, Willems T, De Clercq D, Witvrouw E Relationship between hip strength and frontal plane posture of the knee during a forward lunge. $\mathrm{Br} J$ Sports Med. 2007;41:723-727; discussion 727.

129. Ulkar B, Kunduracioglu B, Cetin C, Guner RS Effect of positioning and bracing on passive position sense of shoulder joint. Br J Sports Med. 2004;38:549-552.

130. van Ingen Schenau GJ, Bobbert MF, Rozendal RH The unique action of bi-articular muscles in complex movements. J Anat. 1987;155:1-5. 
131. Woodland LH, Francis RS Parameters and comparisons of the quadriceps angle of college-aged men and women in the supine and standing positions. Am J Sports Med. 1992;20:208-211.

132. Wyke B The neurology of joints. Ann R Coll Surg (Br). 1967;25:

133. Yu B, Garrett WE. Hamstring co-contraction does not necessarily reduce acl loading. 29th Meeting of the International Society of Biomechanics 20th Congress/American Society of Biomechanics; July 30-August 5, 2005. Cleveland, Ohio; 2005.

134. Yu B, Lin CF, Garrett WE Lower extremity biomechanics during the landing of a stopjump task. Clin Biomech (Bristol, Avon). 2006;21:297-305.

135. Zazulak BT, Hewett TE, Reeves NP, Goldberg B, Cholewicki J Deficits in neuromuscular control of the trunk predict knee injury risk: A prospective biomechanical-epidemiologic study. Am J Sports Med. 2007;35:1123-1130.

136. Zazulak BT, Hewett TE, Reeves NP, Goldberg B, Cholewicki J The effects of core proprioception on knee injury: A prospective biomechanical-epidemiological study. Am J Sports Med. 2007;35:368-373.

137. Zazulak BT, Ponce PL, Straub SJ, Medvecky MJ, Avedisian L, Hewett TE Gender comparison of hip muscle activity during single-leg landing. J Orthop Sports Phys Ther. 2005;35:292-299.

138. Zeller BL, McCrory JL, Kibler WB, Uhl TL Differences in kinematics and electromyographic activity between men and women during the single-legged squat. $\mathrm{Am}$ J Sports Med. 2003;31:449-456. 
APPENDIX A: FLYER

\title{
Are you 18 - 40 years old?
}

\author{
We are looking for \\ HEALTHY FEMALE OR MALE PERSONS \\ to participate in a research study about hip motion and control at the \\ University of Pittsburgh Medical Center
}

- Must be 18 - 40 years old

- Must be physically active (at least 20-30 min activity 3 times/ wk)

- Must have NO hip injury

- Must have NO history of major hip injury or surgery

Participation consists of two visits, total time of participation will be two weeks maximum.

Please contact Anne at anb87@pitt.edu or

412-432-3800 to find out more.

\begin{tabular}{|c|c|c|c|c|c|c|c|c|c|c|c|c|c|}
\hline 胥 & 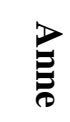 & 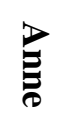 & 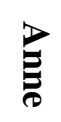 & 胥 & 胥 & 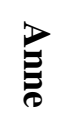 & 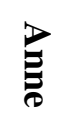 & 胥 & 胥 & 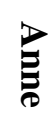 & $\stackrel{P}{E}$ & 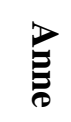 & 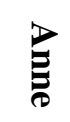 \\
\hline 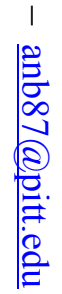 & 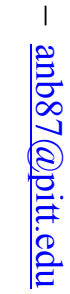 & 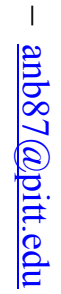 & 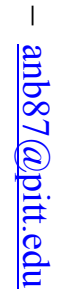 & 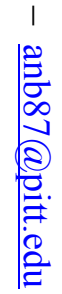 & 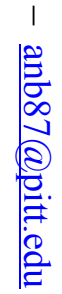 & 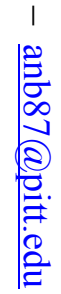 & 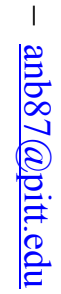 & 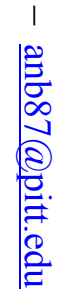 & 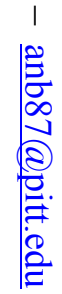 & 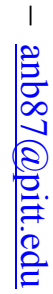 & 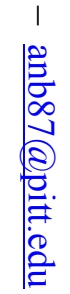 & 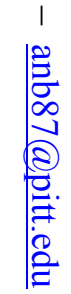 & 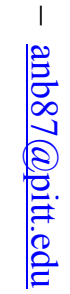 \\
\hline
\end{tabular}




\section{APPENDIX B: PARTICIPANT SCREENING LOG}

PARTICIPANT SCREENING LOG

\begin{tabular}{|c|c|c|c|c|}
\hline \multirow[t]{24}{*}{ PARTICIPANT NAME } & $\#$ & DATE 1 & DATE 2 & COMMENTS \\
\hline & $\frac{1}{2}$ & $01 / 22108$ & $\frac{011<4100}{01129108}$ & $\checkmark 4$ \\
\hline & 3 & 0,129108 & 02120108 & 45 \\
\hline & 4 & $02 / 05108$ & 02128108 & 48 \\
\hline & 5 & $02105 / 08$ & $02111 / 08$ & 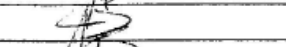 \\
\hline & 6 & $0 / 00 / 00$ & $02122 / 08$ & 45 \\
\hline & 7 & $02107 / 08$ & 02100100 & 4 \\
\hline & 8 & 02107100 & 02118108 & 4 \\
\hline & g & $0=108 / 08$ & $02 / 15 / 08$ & 415 \\
\hline & 10 & $02 / 12 / 108$ & $02118 / 08$ & $x+3$ \\
\hline & 11 & $02 / 15108$ & 02.128108 & -13 \\
\hline & 12 & 02119108 & $02 / 26 / 08$ & $=4 D_{1}$ \\
\hline & 13 & $02 / 20,00$ & 03106108 & 43 \\
\hline & 14 & $02 / 21 / 08$ & 03103108 & $3+2$ \\
\hline & 15 & 02122108 & $03 / 03108$ & \\
\hline & 16 & $02125 / 00$ & $02 / 27 / 00^{\circ}$ & tE \\
\hline & B & $02 / 27 / 08$ & $03105 / 08$ & $\frac{3}{4}$ \\
\hline & 18 & $03103 / 08$ & 03104108 & $4+3$ \\
\hline & 19 & 03104108 & 63107108 & $\pi$ \\
\hline & 20 & 03106108 & $03^{\prime} 107108$ & 10 \\
\hline & & & & \\
\hline & & & & \\
\hline & & & & \\
\hline & & & & 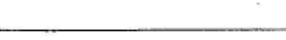 \\
\hline & & & & \\
\hline & & & & \\
\hline & & & & \\
\hline & & & & \\
\hline & & & & \\
\hline & & & & \\
\hline & & & & \\
\hline & & & & \\
\hline & & & & \\
\hline & & & & \\
\hline & & & & \\
\hline & & & & \\
\hline & & & & \\
\hline
\end{tabular}


Study Title: Reliability and precision of hip proprioception methods in healthy individuals IRB \# PRO07060063

Subject \#

\begin{tabular}{|l|l|l|}
\hline Inclusion Criteria & Verified & Comments \\
\hline Age between 18 and 40 years & & \\
\hline $\begin{array}{l}\text { No history of major lower extremity injury or } \\
\text { surgery }\end{array}$ & & \\
\hline No recent (last 6 months) hip injury & & \\
\hline $\begin{array}{l}\text { Physically active (at least 20-30 min activity 3 } \\
\text { times/wk) }\end{array}$ & & Comments \\
\hline & Verified & \\
\hline Exclusion Criteria & \\
\hline $\begin{array}{l}\text { Insulin dependent diabetes mellitus, rheumatologic } \\
\text { disorder, cerebral vascular disorder, or any other } \\
\text { central or peripheral disease that might interfere } \\
\text { with sensory input }\end{array}$ & & \\
\hline $\begin{array}{l}\text { Previous history of cardiovascular or pulmonary } \\
\text { disease }\end{array}$ & & \\
\hline Uncontrolled metabolic disorder & & \\
\hline $\begin{array}{l}\text { Subjects with previous compartment syndrome or } \\
\text { any vascular conditions to their lower leg }\end{array}$ & & \\
\hline $\begin{array}{l}\text { Currently and knowingly pregnant female (any } \\
\text { female subject who is unable to definitively state } \\
\text { that she is not pregnant). And also females who } \\
\text { have been pregnant within the past year }\end{array}$ & & \\
\hline Pain with maximal muscle contractions & & \\
\hline $\begin{array}{l}\text { Skin irritations or abrasion and/or any history of } \\
\text { allergy to adhesive tape }\end{array}$ & & \\
\hline Central and/or peripheral nervous system disorders & & \\
\hline
\end{tabular}

Date:

Investigator's signature: 


\section{APPENDIX D: PROCEDURE CHECKLIST}

\section{Day 1}

Subject \#:

Date:

\begin{tabular}{|l|l|l|}
\hline Procedure & Completed & Comments \\
\hline Informed consent & & \\
\hline Inclusion/exclusion & & \\
\hline Explanation general procedures & & \\
\hline Demographic information & & \\
\hline Generalized laxity testing & & \\
\hline Hip ROM testing & & \\
\hline Anthropometric measurements & & \\
\hline Active JPS testing (Vicon motion analysis) & & \\
\hline TTDPM testing (Biodex) & & \\
\hline FS testing (Biodex) & & \\
\hline
\end{tabular}

Did the subject have any questions regarding informed consent and testing procedures?

Yes No

Notes:

Individual present:

Investigator's signature: 


\section{Day 2}

Subject \#:

Date:

\begin{tabular}{|l|l|l|}
\hline Procedure & Completed & Comments \\
\hline Informed consent & & \\
\hline Inclusion/exclusion & & \\
\hline Explanation general procedures & & \\
\hline Demographic information & & \\
\hline Generalized laxity testing & & \\
\hline Hip ROM testing & & \\
\hline Anthropometric measurements & & \\
\hline Active JPS testing (Vicon motion analysis) & & \\
\hline TTDPM testing (Biodex) & & \\
\hline FS testing (Biodex) & & \\
\hline
\end{tabular}

Did the subject have any questions regarding informed consent and testing procedures?

Yes No

Notes:

Individual present:

Investigator's signature: 


\section{APPENDIX E: NARRATIVE NOTE}

I certify that the nature and purpose, the potential benefits, and possible risks associated with participation in this research study have been explained to subject \# and that any questions about this information have been answered.

Investigator's signature

Date 


\section{APPENDIX F: DEMOGRAPIC INFORMATION}

Age

Height

Weight

Gender

Subject \#

Tegner Activity Level

10. Competitive sports

Soccer-national and international elite

9. Competitive sports

Soccer, lower divisions

Ice hockey

Wrestling

Gymnastics

8. Competitive sports

Bandy

Squash or badminton

Athletics(jumping, etc)

Downhill skiing

7. Competitive sports

Tennis

Athletics(running)

Motorcross, speedway

Handball

Basketball

Recreational sports

Soccer

Bandy and ice hockey

Squash

Athletics(jumping)

Cross-country track findings both recreational and competitive

6. Recreational sports

Tennis and badminton

Handball

Basketball

Downhill skiing

Jogging, at least five times per week

5. Work

Heavy labor(e.g., building, forestry)

Competitive sports

Cycling

Cross-country skiing

Recreational sports

jogging on uneven ground at least twice weekly

4. Work

Moderately heavy labor

(e.g., truck driving, heavy domestic work)

Recreational sports

Cycling

Cross-country skiing

Jogging on even ground at least twice weekly

3. Work

Light labor(e.g., nursing)

Competitive and recreational sports

Swimming

Walking in forest possible

2. Work

Light labor

Walking on uneven ground possible but impossible to walk in forest

1. Work

Sedentary work

Walking on even ground possible

0 . Sick leave or disability pension because of knee problems

Date:

Investigator's signature: 


\section{APPENDIX G: PHYSICAL EXAMINATION}

\section{SUBJECT \#}

\begin{tabular}{|l|l|}
\hline Direction & Result $^{\left({ }^{\circ}\right.}$ \\
\hline IR & \\
\hline ER & \\
\hline ABD & \\
\hline ADD & \\
\hline FLEX & \\
\hline EXT & \\
\hline
\end{tabular}

\begin{tabular}{|l|l|l|}
\hline Task & Right & Left \\
\hline 1. Passively dorsiflex the $5^{\text {th }}$ metacarpophalangeal joint to $\geq 90^{\circ}$ & & \\
\hline 2. Oppose the thumb to the volar aspect of the ipsilateral forearm & & \\
\hline 3. Hyperextend the elbow $\geq 10^{\circ}$ & & \\
\hline 4. Hyperextend the knee $\geq 10^{\circ}$ & & \\
\hline 5. Place hands on the floor without bending the knees & & \\
\hline Total score & & \\
\hline
\end{tabular}

Date:

Investigator's signature: 


\section{APPENDIX H: CORRELATION ANALYSIS}

$\mathrm{P}$ values reported in this appendix are one tailed.

Correlations ( $r$ ) for between day differences for JPS

\begin{tabular}{|l|c|c|c|c|c|c|c|}
\hline & Laxity & IRROM & ERROM & ABDROM & ADDROM & FLEXROM & EXTROM \\
\hline ER & 0.093 & 0.190 & -0.002 & 0.368 & 0.175 & -0.013 & 0.084 \\
\hline IR & -0.131 & 0.072 & -0.167 & -0.085 & 0.165 & -0.201 & 0.280 \\
\hline FLEX & -0.101 & -0.019 & -0.234 & -0.306 & 0.162 & 0.249 & -0.297 \\
\hline ABD & 0.102 & 0.035 & -0.128 & 0.132 & $\mathbf{- 0 . 3 9 4} *$ & -0.183 & -0.250 \\
\hline ADD & 0.132 & 0.058 & $\mathbf{0 . 4 1 3}$ & 0.312 & 0.044 & 0.233 & $\mathbf{0 . 5 9 4}$ \\
\hline
\end{tabular}

* Significant correlation $P<0.05$

Correlations ( $r$ ) for between day differences for FS

\begin{tabular}{|l|c|c|c|c|c|c|c|}
\hline & Laxity & IRROM & ERROM & ABDROM & ADDROM & FLEXROM & EXTROM \\
\hline FLEX & 0.110 & 0.118 & -0.322 & 0.356 & -0.149 & -0.231 & -0.024 \\
\hline EXT & -0.310 & -0.294 & -0.369 & 0.113 & $\mathbf{- 0 . 6 1 6 *}$ & $\mathbf{- 0 . 5 7 2} *$ & $\mathbf{- 0 . 5 5 7 *}$ \\
\hline ABD & 0.164 & -0.124 & $\mathbf{- 0 . 5 6 6}$ & -0.028 & 0.179 & 0.327 & $\mathbf{0 . 4 2 1}^{*}$ \\
\hline ADD & -0.010 & -0.030 & -0.149 & -0.304 & 0.175 & -0.165 & 0.151 \\
\hline
\end{tabular}

* Significant correlation $P<0.05$

Correlations ( $r$ ) for between day differences for TTDPM

\begin{tabular}{|l|c|c|c|c|c|c|c|}
\hline & Laxity & IRROM & ERROM & ABDROM & ADDROM & FLEXROM & EXTROM \\
\hline FLEX & -0.083 & 0.017 & 0.047 & -0.024 & $\mathbf{0 . 3 8 0}$ & 0.279 & $\mathbf{0 . 4 6 5}$ \\
\hline EXT & 0.340 & 0.091 & 0.097 & -0.199 & 0.247 & $\mathbf{0 . 4 9 6}^{*}$ & $\mathbf{0 . 4 2 6}^{*}$ \\
\hline ABD & -0.123 & -0.014 & -0.139 & $\mathbf{- 0 . 4 8 4}$ & $\mathbf{0 . 3 9 1}$ & 0.106 & 0.250 \\
\hline ADD & -0.094 & 0.063 & -0.260 & $\mathbf{- 0 . 3 8 9 *}$ & 0.262 & 0.207 & 0.157 \\
\hline
\end{tabular}

* Significant correlation $P<0.05$ 
APPENDIX I: BETWEEN DAY RELIABILITY OF HIP ROM MEASUREMENTS

\begin{tabular}{|c|c|}
\hline DIRECTION & $\begin{array}{c}\text { INTERSESSION } \\
\text { ICC }\end{array}$ \\
\hline IR & 0.844 \\
\hline ER & 0.865 \\
\hline ABD & 0.888 \\
\hline ADD & 0.846 \\
\hline FLEX & 0.925 \\
\hline EXT & 0.838 \\
\hline
\end{tabular}

